\title{
Sistema Integrado de Estimativa e Previsão de Precipitação para Bacias Hidrográficas da CESP
}

\author{
Augusto José Pereira Filho ${ }^{1 \#}$ (D), Mírian Adelaide R.R. Costa Pinto ${ }^{2}$, Laércio Manfredini ${ }^{3}$, \\ Fabiano Alves de Lima ${ }^{3}$, Amarílio Costa e Carvalho Pinto ${ }^{2}$, Carlos H. Moribe ${ }^{2}$, \\ Felipe Vemado $^{1}$ (D) Ivon Wilson da Silva Júnior ${ }^{1}$ \\ ${ }^{1}$ Departamento de Ciências Atmosféricas, Instituto de Astronomia, Geofísica e Ciências \\ Atmosféricas, Universidade de São Paulo, São Paulo, SP, Brasil. \\ ${ }^{2}$ Hedaide Engenharia, São Paulo, SP, São Paulo, SP, Brasil. \\ ${ }^{3}$ Companhia Energética de São Paulo, São Paulo, SP, Brasil.
}

Recebido em: 30 de Maio de 2019 - Aceito em: 3 de Fevereiro de 2020

\begin{abstract}
Resumo
A previsão de vazão é uma das mais importantes informações na programação da geração de energia hidroelétrica e no planejamento de curto a longo prazo. A previsão de vazão é mais relevante em cenários de escassez hídrica, quando há redução da geração hidroelétrica e aumento da produção por usinas termelétricas para garantir outros usos da água nessas condições. Prever e prognosticar a precipitação por meio de modelos estocásticos e determinísticos é essencial mesmo com as limitações inerentes à complexidade fenomenológica atmosférica. Estabelecer diretriz com base em tais modelos fundamentados em variáveis hidrometeorológicas (e.g., séries de precipitação) e fenômenos climáticos podem reduzir erros e melhorar a operação de reservatórios. O Operador Nacional do Sistema (ONS) e agentes de geração podem decidir com menos riscos operacionais, otimizar os recursos energéticos, minimizar custos para o consumidor e suprir energia elétrica mesmo em períodos de escassez hídrica. Assim, este trabalho apresenta um sistema de monitoramento e previsão de precipitação nas bacias hidrográficas da CESP para melhorar as estimativas de vazão afluentes aos seus reservatórios. A previsão de chuva com até cinco dias de antecedência foi realizada com o sistema ARPS. As estimativas, medições e simulações de chuva obtidas foram utilizadas em simulações de vazão afluente nas bacias da CESP com o modelo SMAP para verificação. Os resultados sugerem melhoria de desempenho por meio da integração de dados e previsão de precipitação com o sistema ARPS.
\end{abstract}

Palavras-chave: análise objetiva estatística, precipitação, rede telemétrica, sistema ARPS, modelo SMAP.

\section{CESP Integrated Precipitation Estimation and Forecasting System for its} Watersheds

\begin{abstract}
Flow forecasting is one of the most important information to scheduling hydroelectric power generation and short- to long-term planning. Flow prediction is most relevant in water scarcity scenarios, when there is a reduction in hydroelectric power generation and an increase in production by thermoelectric plants to guarantee other uses of water under such conditions. The prediction and prognostic precipitation through stochastic and deterministic models is essential even with the inherent limitations of atmospheric phenomenological complexity. Establishing guidelines upon such models based on hydrometeorological variables (e.g., precipitation time series) and climate phenomena can reduce errors and improve reservoir operations. The National System Operator (ONS) and generation agencies may decide with fewer operational risks in order to optimize energy resources, minimize consumer costs and supply electricity even in times of water scarcity. Thus, this paper describes a rain monitoring and forecasting system in the CESP watersheds to improve the streamflow estimation of CESP reservoirs. We present an objective statistical analysis scheme (ANOBES) that integrates the meteorological satellite precipitation estimation with CESP, DAEE and ANA telemetric network rainfall measurements. Rain forecasting up to five days in advance is performed with the ARPS system. The estimates, measurements and rainfall simulations obtained were used in tributary flow simulations of CESP watersheds with the
\end{abstract}

Autor de correspondência: Augusto José Pereira Filho, augusto.pereira@iag.usp.br. 
SMAP model for verification. Rain forecast up to five days in advance was made with the ARPS system. The estimates, measurements and rainfall simulations obtained were used in tributary flow simulations in CESP basins with the SMAP model for verification. The results suggest performance improvement with data integration and precipitation prediction with the ARPS system.

Keywords: statistical objective analysis, precipitation, telemetric network, ARPS system, SMAP model.

\section{Introdução}

O sistema de produção de energia elétrica brasileiro é hidrotérmico, ou seja, utiliza a combinação de usinas hidrelétricas, termelétricas e outras fontes alternativas de geração de energia. Dentre as diversas fontes de geração de energia no Brasil, destaca-se a de origem hidráulica, a partir de hidrelétricas, o que envolve importantes riscos de oferta, já que o principal insumo, a água, é a vazão dos rios que, por sua vez, é dependente do clima e de sua variabilidade temporal e espacial. Pelas características das bacias hidrográficas brasileiras e das topologias das regiões, as usinas hidrelétricas foram construídas com reservatórios de acumulação, que permitem a regularização, e reservatórios a fio d'água, sem capacidade de armazenamento.

A vazão de um rio em uma determinada usina é o resultado da vazão proveniente da precipitação que ocorre sobre seu lago através do escoamento direto (superficial) e escoamento básico (subterrâneo), da vazão afluente dos rios tributários, da exploração dos usos múltiplos, da evapotranspiração, acumulação ou exploração em reservatórios, dentre outros usos, que, ao somá-las, compõem o balanço hídrico. Das variáveis que fecham o balanço hídrico, a precipitação, consequentemente a vazão associada à chuva, é tida como a variável de menor previsibilidade por meio dos modelos matemáticos que descrevem a atmosfera. A previsão de vazão usa um conjunto de procedimentos para estimar a vazão e reduzir as incertezas relacionadas às condições climáticas futuras. Para ampliar o horizonte da previsão, é necessário, então, prevver a precipitação futura com bastante antecedência. Entretanto, essa não é uma tarefa fácil, pois acertar, ou errar, a previsão de chuvas, ou a ausência delas, num horizonte futuro de meses, e até mesmo anos, depende dos resultados de modelos de previsão, que trabalham com dados recentes e séries sintéticas de dados, prevendo probabilidades futuras do comportamento hidrológico.

A previsão de vazão em um sistema hídrico consiste na estimativa do escoamento de um curso d'água para um horizonte e é uma das técnicas utilizadas para minimizar o impacto das incertezas do clima sobre o gerenciamento dos recursos hídricos. Previsões auxiliam na implantação de sistemas de alerta contra cheias, permitindo uma maior antecipação do início das ações de mitigação dos possíveis danos materiais, sociais e humanos decorrentes de eventos extremos. A utilização de previsões hidrológicas subsidia o processo de tomada de decisão, podendo trazer benefícios pela redução dos danos decorrentes de cheias, pelo aumento da segurança da barragem e pela maior eficiência na geração de energia. Porém, os benefícios da previsão dependem da eficiência dos modelos de previsão e da forma como a informação da previsão é incorporada na tomada de decisões sobre a operação dos reservatórios, que é fortemente dependente do conhecimento antecipado de condições atmosféricas e hidrológicas para diferentes escalas de tempo e espaço. A escala temporal da previsão de vazão depende do horizonte do estudo, da finalidade do estudo e do modelo de tomada de decisão em que será incorporada.

O planejamento energético busca o melhor binômio "requisito versus recurso". De um lado, tem-se a carga a ser atendida e de outro a produção de energia. O que parece ser mais eficiente, à primeira vista, é atender à demanda com geração hidráulica, mas esse procedimento implica deplecionar os reservatórios. Por outro lado, quanto mais cheios se mantiverem esses mesmos reservatórios mais certo será o atendimento quanto à demanda futura, pois reduzirá a possibilidade de escassez de recursos no futuro.

É necessário então que haja um despacho ótimo, que faz com que a sociedade receba energia ao menor custo, com qualidade e confiabilidade. Não se pode olhar o despacho ótimo apenas sob o aspecto energético. É preciso que ele atenda às restrições ambientais de uso múltiplo da água e, principalmente, que esteja adequado à topologia da malha de transmissão para aquela situação, considerandose aí os desligamentos e as indisponibilidades de linhas e equipamentos que possivelmente possam ocorrer. Se o sistema brasileiro fosse puramente térmico, o problema seria determinístico. Haveria uma carga a ser atendida e conhecer-se-ia a quantidade de máquinas térmicas, o combustível e o custo desse combustível. Como o sistema brasileiro é, em grande parte, atendido por geração hidráulica, as incertezas associadas às afluências futuras dotam o problema de uma característica estocástica. É preciso, então, optar onde e quanto gerar de hidráulicas e térmicas para evitar déficit futuro.

O Operador Nacional do Sistema Elétrico (ONS) com sua visão sistêmica e como responsável pela otimização da operação, coordena, com todos os agentes, o uso compartilhado da água em cada trecho de todos os rios, de forma a garantir o melhor aproveitamento hidroenergético sem comprometer o meio ambiente e o uso compartilhado da água. No planejamento de longo prazo, o setor elétrico utiliza o modelo computacional de otimização denominado NEWAVE. Esse modelo faz parte da cadeia de modelos energéticos e é utilizado para fazer mensalmente o Programa Mensal da Operação, com horizonte de 5 anos 
de estudo, pelo Operador Nacional do Sistema Elétrico ONS. Nesse caso, as séries históricas de vazão por postos são convertidas em energia e agrupadas em quatro subsistemas para o modelo gerar 2000 séries sintéticas de energia, com discretização mensal. O modelo otimiza o custo de operação do sistema para o horizonte de estudo com base nesses 2000 cenários de vazão buscando o melhor uso dos recursos hídricos. Com o resultado desse modelo, ainda se calcula o risco de déficit de energia para os próximos anos e a profundidade desse déficit. Para o planejamento de curto prazo, o operador utiliza o modelo DECOMP para o horizonte de até 2 meses, com discretização semanal no primeiro mês e mensal no segundo mês. O DECOMP adota vazão por posto, ou seja, cada usina tem sua previsão de vazão e é dada como determinística no primeiro mês, ou seja, existe apenas um valor de vazão para cada usina e cada estágio, que é calculado pelo previsor. Já no segundo mês, o modelo de previsão de vazão GEVAZP gera uma árvore de possibilidades de vazão. Nas semanas do primeiro mês, cada bacia dispõe de um previsor que utiliza diferentes metodologias que mais se adequam à característica local. Das metodologias destacam-se: SMAP, MGB, FUZZY, Regredido/Calculado, PrevivazH, Neuro 3M, CPINS, média e previsões próprias de agentes.

Desta forma, o ONS deve tomar a decisão, baseado nos resultados dos modelos de otimização. Sem conhecimento do futuro, o ONS pode tomar quatro medidas, sendo que duas delas são positivas para a sociedade e as outras duas podem causar grandes prejuízos, principalmente para a economia do país. Tomar a decisão de utilizar os reservatórios nos períodos de escassez pode gerar déficit energético no futuro e com isso causar um racionamento ou corte de fornecimento de energia ao país. Por outro lado, adotar uma medida de poupar os recursos hídricos, maximizando a geração térmica e acontecer um período úmido bastante favorável, poderá levar a vertimentos nas usinas, que significa jogar energia fora, além de haver o despacho das usinas térmicas quando deverão ser pagos preços bem mais altos do que as hidrelétricas. É muito difícil para o operador tomar essa decisão. Os modelos de previsão de vazão associados ao modelo de otimização auxiliam muito na tomada de decisão, de forma a se adotar o caminho ótimo de operação, com minimização de erros e dos riscos. Nota-se que as afluências futuras são o cerne da questão e que preocupam, sobremaneira, o modo do sistema elétrico brasileiro. No horizonte de curto prazo, para a operação individualizada de cada usina hidrelétrica, a questão das afluências futuras também é preocupante. Com uma estimativa de afluência bem aferida, é possível que se aproveitem melhor os recursos do reservatório ao se evitar vertimentos turbináveis, sendo ainda possível escolher uma melhor janela de datas para uma eventual manutenção programada. No âmbito da programação diária, a previsão de vazão também tem sua importância, pois o programador planeja a operação das usinas diariamente, mas sempre com vistas nas consequências das decisões em um horizonte de até 7 dias à frente. Tendo como base a previsão de precipitação para os próximos dias, o programador utiliza um modelo chuvavazão que transforma essa previsão de chuva em vazão, considerando diversos fatores do ambiente, como as chuvas que ocorreram dias atrás. Na programação diária, é onde se têm os valores mais refinados de vazão e com impactos muito significativos caso o valor previsto esteja muito aquém do valor realizado.

Nos modelos de planejamento de curto e longo prazo, há uma projeção de vazão num horizonte de até 5 anos para fins puramente energéticos, ou seja, os modelos otimizam o custo de operação do sistema com base na quantidade de energia fornecida pelos previsores de vazão (séries sintéticas ou históricas). De maneira diferente, na programação diária, deve haver um valor da previsão de vazão mais assertivo, pois o principal impacto é operacional, que envolve principalmente a segurança do empreendimento. O programador deve conhecer com grande exatidão a quantidade de água que chegará na sua usina para não comprometer o nível do lago montante, com um excesso de geração ou provocar um vertimento, e até ocasionalmente um vertimento turbinável, em razão de um elevado nível do lago que não foi previsto. Parte da vazão da usina depende da defluência da usina a montante, quando existir, e parte vem de rios tributários e de precipitações que ocorrem em toda a área de drenagem da bacia. Como exemplo, em um período de controle de cheias, as decisões são tomadas, em alguns casos, em tempo real, já que a vazão pode aumentar significativamente em função de uma chuva forte não esperada. Muitas dessas decisões podem ser evitadas caso haja uma previsão de vazão bem apurada onde se consegue alocar um volume de espera suficientemente grande para absorver essas ondas de vazão, com a atenção necessária de não comprometer o estoque para garantir o suprimento no período de seca.

A previsão de vazão não é uma tarefa simples, mas a consequência que uma previsão malfeita ou bem-feita pode trazer ao sistema é bastante significativa. Caso haja um excesso de vazão não esperado, os reservatórios podem não absorver essa quantidade de água e causar grandes transtornos à população ribeirinha ou até mesmo à cidades, como ocorreu em São Luiz do Paraitinga, no interior de São Paulo, na ocasião em que a vazão do rio Paraíba do Sul alagou grande parte da cidade. Na região sul e norte do país, as altas vazões causam grandes prejuízos às cidades, onde pessoas têm que sair de suas residências tomadas pelas águas do rio. Para amenizar essa situação, minimizar os riscos e aumentar a segurança, tanto dos empreendimentos quanto de suprimento energético, o ONS realiza anualmente o Plano Anual de Prevenção de Cheias - PAPC. Tal plano consiste em um estudo com diretrizes que o operador deve tomar con- 
forme ocorrer cenários de vazões. O plano possui diretrizes da operação dos reservatórios, como a alocação do volume de espera que é uma maneira de se deixar um volume vazio no reservatório que seja capaz de absorver uma onda de vazão que porventura possa ocorrer. À medida que vai se aproximando do término do período chuvoso, o volume de espera tende a diminuir, de tal sorte que se possa armazenar o máximo de água para garantir o suprimento no período seco.

O fator segurança é muito importante, e as usinas da CESP possuem um manual denominado Sistema de Operação em Situação de Emergências - SOSEm, que consiste em um conjunto de normas e procedimentos de operação e manutenção envolvendo aspectos técnicos, organizacionais e administrativos. O objetivo do SOSEm é garantir a máxima segurança da operação hidráulica dos seus reservatórios para buscar a segurança, proteção a jusante, descentralização de comando, responsabilidade pelo risco, segurança à comunidade, veiculação de informações, retorno à situação normal e produção da energia, navegação e de outros usos. A previsão de vazão faz-se muito importante na decisão de operação diária e em tempo real durante um período de controle de cheias. O manual SOSEm particulariza casa usina da CESP e a forma de operação, além das situações dos reservatórios, durante um período de cheias. Esse manual também atribui responsabilidades e auxilia as decisões de operação baseadas em diagramas que considera, dentre outras variáveis, a vazão.

O ONS possui o submódulo de previsão de vazão e cenários de afluências dentro dos procedimentos de rede que trata exclusivamente de vazão. Esse submódulo estabelece os processos para a previsão de vazões mensais, semanais e diárias e para a geração de cenários de afluências naturais médias mensais utilizados na elaboração do Programa Mensal da Operação Energética - PMO e suas revisões semanais e do Programa Diário de Operação PDO. As previsões de vazões diárias também são utilizadas na programação diária da operação eletroenergética. Além disso, ainda atribui responsabilidades de agentes e do próprio operador. Os produtos disponibilizados pelo ONS, através desse submódulo, são: relatório de vazões médias diárias; relatório de previsão de vazões e geração de cenários de afluências; relatório anual de avaliação das previsões de vazões. Dentre as responsabilidades do ONS, destaca-se: a) obter as informações e dados necessários para a realização da previsão de vazões (vazões naturais verificadas, informações meteorológicas e climáticas); b) receber previsões de vazão natural dos agentes de geração; c) obter dos agentes de geração informações sobre as metodologias, os modelos e os sistemas utilizados para as previsões de vazões; d) processar os modelos de previsão de vazão.

Resumidamente, a previsão de vazão é um dos mais importantes insumos, seja no planejamento de longo e de curto prazo, na programação diária, no tempo real e no controle de cheias. Atualmente, a previsão de vazão é importante inclusive em momentos de crise hídrica, que impacta diretamente na crise energética. A falta de água impacta no despacho adicional de usinas termelétricas para garantir o suprimento energético, impactando em altos custos na produção, além de poupar água nos reservatórios para os outros usos. Quantificar e estimar a quantidade de água que estará disponível no futuro é uma tarefa bastante complexa sujeita a erros significativos. Entretanto, criar uma diretriz com base em modelos que consideram diversas variáveis como séries de precipitação e prognósticos, além de fenômenos climáticos podem diminuir erros e otimizar a operação de reservatórios. Com isso, o ONS e agentes de geração terão a capacidade de tomar a melhor decisão, visando à otimização dos recursos energéticos e à minimização do custo para o consumidor, além de garantir o suprimento, mesmo nos períodos de crise.

Portanto, o presente estudo compreende o desenvolvimento de um sistema de monitoramento e previsão de chuva nas bacias hidrográficas de interesse da CESP (Fig. 1). Concomitantemente, pretendeu-se melhorar as estimativas de vazão afluentes aos reservatórios da CESP por meio da integração da estimativa de precipitação por satélite meteorológico com medidas de pluviômetros de redes telemétricas. O sistema assim constituído permitirá a automatização de análises, disseminação e integração de estimativas de precipitação e da previsão de precipitação nas bacias monitoradas pelo sistema de previsão hidrológica da CESP. Complementarmente, capacitarão técnicos para utilização do novo sistema de informações hidrometeorológicas, com vistas a produzir melhorias na operação hidráulica e na geração de energia elétrica nos aproveitamentos operados pela CESP.

A geração de energia elétrica por meio de usinas hidrelétricas depende da disponibilidade hídrica de reservatórios e da precipitação na bacia hidrográfica. Ambos estão condicionados à intensidade, duração e distribuição da precipitação na bacia hidrográfica. Assim, monitorar e prever a quantidade de precipitação na bacia é fundamental para determinar o volume de água que será armazenado e utilizado na geração de energia.

A vazão é estimada por modelo de simulação hidrológica (SMAP), que permite prever as vazões nas bacias hidrográficas com base nas previsões de chuva. As previsões de vazão facilitam a operação hidráulica dos reservatórios. Como os pluviômetros medem a precipitação num determinado ponto, a representatividade espacial das medições, além de efeitos de exposição, resulta em erros, que são menores para sistemas precipitantes convectivos isolados, pois a precipitação ocorre em áreas pequenas (10 km de diâmetro ou menos). Radares meteorológicos possuem uma suficiente representatividade espacial e temporal na estimativa da precipitação, mas com várias fontes 


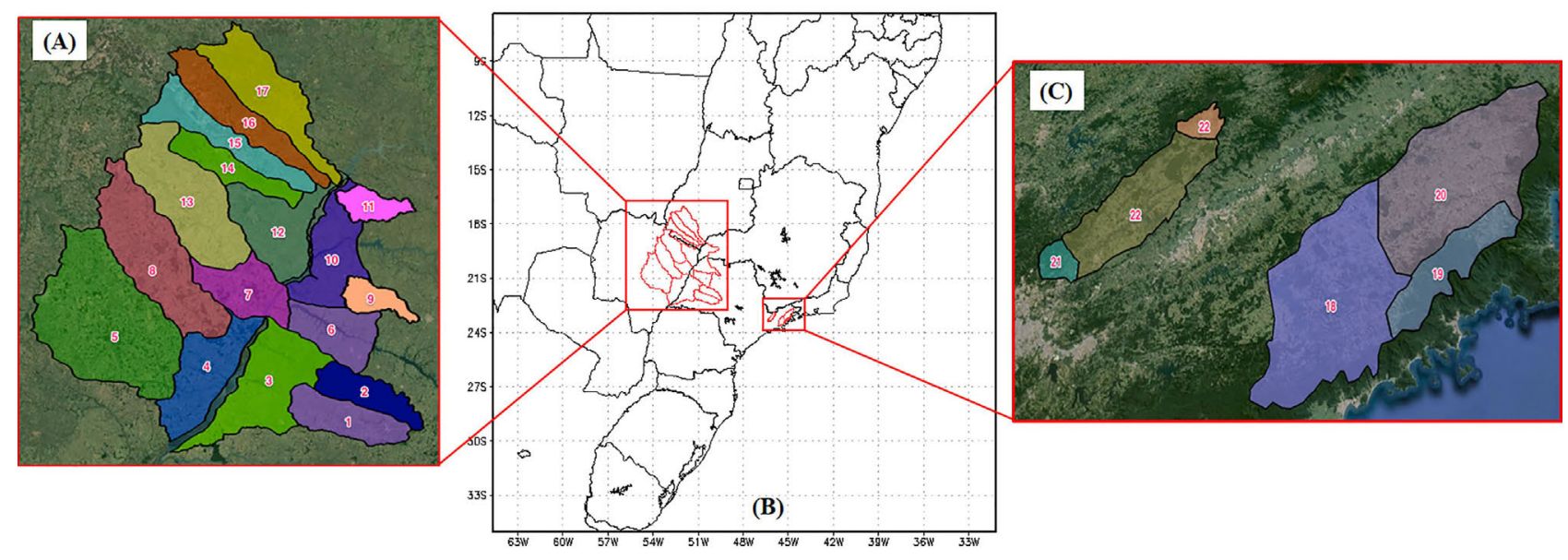

Figura 1 - Bacias hidrográficas do rio Paraná (trecho entre as UHEs São Simão, Água Vermelha e Porto Primavera) (esquerda-alto) e do rio Paraíba do Sul (montante às UHEs Paraibuna e Jaguari) (centro-baixo). Ordem, nome e sigla de cada sub-bacia: 1-Flórida Paulista (FLT); 2-Salto Carlos Botelho (SCB); 3-Leste Lago Primavera (VLP); 4-Oeste Lago Primavera (VOP); 5-Fazenda Buriti (FBU); 6-Lago 3 Irmãos (TRI); 7-Lago Jupiá (JUP); 8-Porto Velho (POV); 9-Fazenda Palmeirinha (FPA); 10-Leste Ilha Solteira (VLI); 11-Ponte São Domingos (PSD); 12-Oeste Ilha Solteira (VOI); 13-Fazenda São Sebastião (FSS); 14-Fazenda Balsamo (FBA); 15-Fazenda Mumbela Inferior (FAM); 16-Fazenda Mumbela Superior (FAL); 17-Jataí (FRO); 18-Paraibuna (PAR); 19-Fazenda Palmeiras (FAP); 20-São Luiz do Paraitinga (SLP); 21-Cachoeira do Jaguaribe (CAJ); 22-Jaguari (JAG); 23-Fazenda Santana (FAZ). Fonte: GoogleMap. Posição geográfica das sub-bacias mostrada no detalha (direita-alto).

de incertezas e erros na estimativa da intensidade. Estimativas por satélite são vantajosas por terem uma ampla área de cobertura (América do Sul, por exemplo), mas com restrições na estimativa da intensidade imposta pela menor resolução temporal.

Portanto, cada sensor apresenta vantagens e desvantagens, o que sugere a integração de todas as estimativas para compor um campo cada vez mais próximo da realidade. A integração de medidas e estimativas de chuva das várias plataformas pressupõe a análise objetiva por meio de métodos que considerem as características e limitações de cada sensor e fenômenos meteorológicos que deverão ser detectados. Os sistemas modernos de previsão de precipitação incluem, além de sistemas avançados de integração de informações hidrometeorológicas, modelos numéricos de previsão de tempo nas escalas global e regional. Esses modelos realizam simulações a partir de uma condição inicial do estado da atmosfera e, por meio de equações hidro e termodinâmicas complexas, realizam simulações prognósticas do comportamento da atmosfera.

Assim, é fundamental que sejam feitas medições acuradas para representar adequadamente os diversos fenômenos meteorológicos atuantes, principalmente no Brasil, onde há uma grande carência de dados. Por essa razão, agregar informações disponíveis é importante para obter um campo inicial mais acurado. A assimilação de campos de variáveis em modelos numéricos permite melhorar o desempenho das simulações numéricas e obter melhores prognósticos de precipitação e da formação de tempestades para curto e médio prazo.

Os objetivos desta pesquisa e desenvolvimento foram: 1) integrar a estimativa de precipitação por meio de dados de satélite meteorológico METEOSAT SEGUNDA GERAÇÂO (MSG) com medidas de redes telemétricas da CESP, DAEE e ANA; 2) estabelecer um sistema de previsão de precipitação com assimilação de dados do sistema integrado de estimativa de precipitação e modelo numérico de previsão de tempo de curto e médio prazo para as bacias dos rios Grande, Paraibuna e Jaguaribe; 3) Desenvolver um sistema automático de análise, disseminação e integração de estimativas de precipitação e de previsão de precipitação nas bacias para a operação do sistema de previsão hidrológica da CESP; 4) treinar técnicos para utilizar o novo sistema de informações hidrometeorológicos; 5) aprimorar e melhorar a operação e eficiência de geração de energia nas áreas de operação da CESP.

A seguir são descritos a metodologia e os resultados.

\section{Material e Métodos}

O fluxograma do sistema de previsão hidrometeorológica integrado está mostrado na Fig. 2. Os modelos utilizados são: 1) modelagem numérica com ARPS (Advanced Regional Prediction System) (Xue et al., 1995; Xue et al., 2000; Xue et al., 2001; Xue et al., 2003; Xue e Martin, 2006; Hallak, 2007; Vemado, 2012)-trata-se de um sistema de previsão numérica do tempo, que permite obter a precipitação acumulada com resolução espacial de $12-\mathrm{km}$ e temporal de 1 hora para um período de até cinco dias de antecedência; os dados iniciais e condições de contorno foram obtidos do modelo global GFS (Global Forecasting System) (Eanglin et al., 2006; Han e Pan, 2011; Juang et al., 2011; Zheng et al., 2012) e a umidade do solo foi ajustada durante o processamento de forma a melhorar os resultados; 


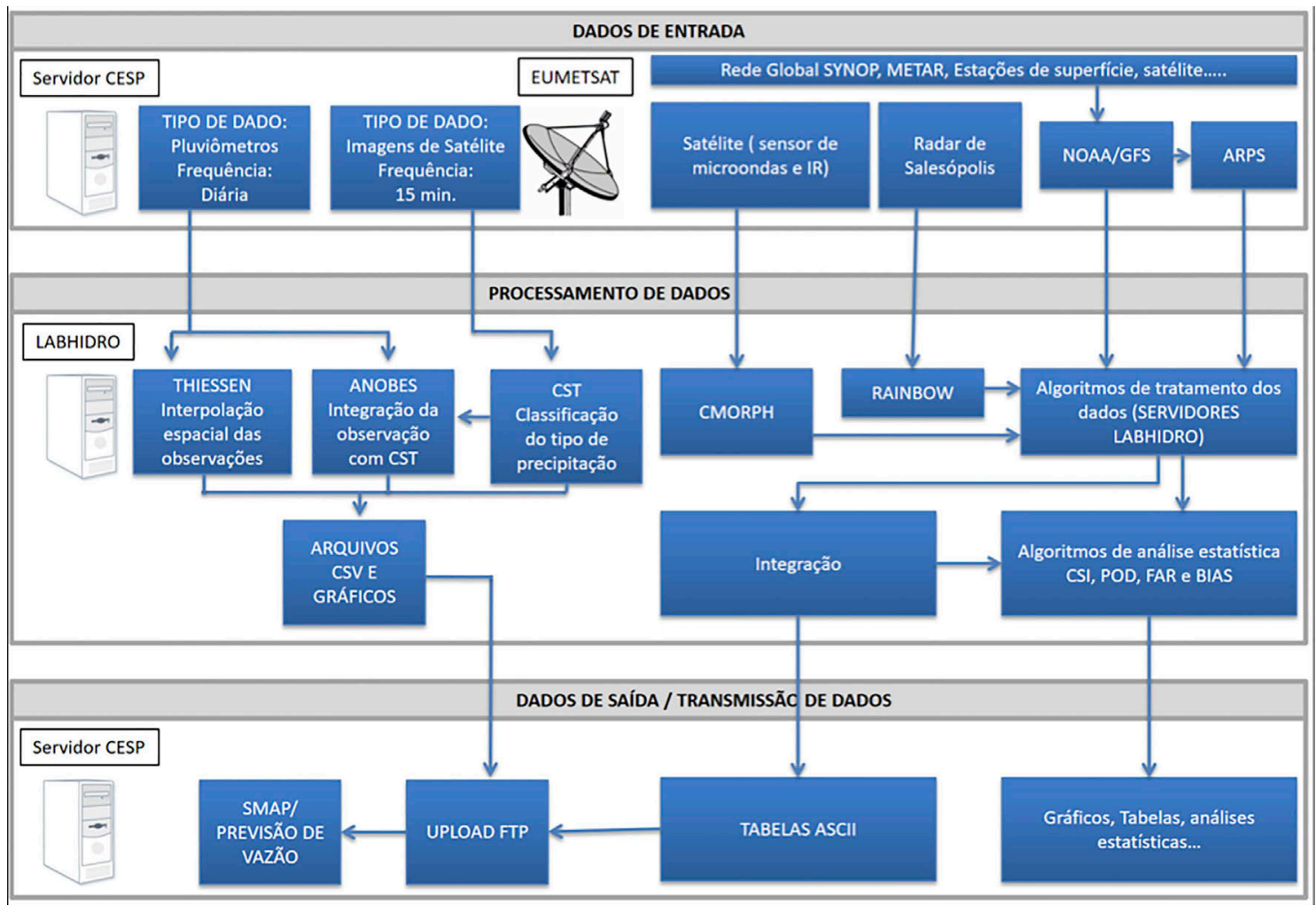

Figura 2 - Fluxograma do Sistema de Previsão Hidrometeorológica (SPH) da CESP. Estão indicados os bancos de dados, servidores, sistema de processamento, análise de dados armazenamento e fluxo de disseminação de informações com a ordem das respectivas etapas de desenvolvimento.

a precipitação prevista foi avaliada por meio de método estatístico com dados da rede de superfície e estimativa de satélite CMORPH (Climate Prediction Center Morphing Technique) (Joyce et al., 2004), que também foram utilizados na modelagem hidrológica com o SMAP (Soil Moisture Accounting Procedure) (Lopes et al., 1982; Lopes et al., 1991); 2) modelagem numérica com GFS - trata-se de um modelo numérico global com resolução espacial de $25-\mathrm{km}$ e temporal de 3 horas para até 16 dias à frente; os dados do modelo foram assimilados no sistema ARPS até cinco dias à frente, e também utilizados para estimar a precipitação média nas bacias da CESP entre seis e quinze dias; 3 ) estimativa de chuva com CST (Convective Stratiform Technique) (Negri et al., 2002; Pereira Filho et al., 2004; Pereira Filho et al., 2003): trata-se de uma técnica de estimativa de chuva horária por meio de dados do infravermelho do satélite europeu MSG (Meteosat Second Generation), com resolução espacial de $8-\mathrm{km}$ e temporal de 15 minutos; determina-se o tipo de precipitação, convectiva ou estratiforme, e designa-se a esta uma taxa de precipitação constante, que é integrada no intervalo de 1 hora e de 24 horas; neste caso, a inovação verificada no estudo é o aumento da resolução temporal dos dados, que permite amostrar melhor o sistema de precipitação de rápido desenvolvimento e decaimento (convectivo); 4) estimativa de precipitação com Thiessen - trata-se de analisar a precipitação medida pela rede telemétrica da CESP por meio de um método geométrico denominado Thiessen, apropriado para redes de superfície esparsas e com distribuição heterogênea; é considerada a melhor opção no caso da ausência de outras fontes de dados; 5) integração de chuva ANOBES (Creutin e Obled, 1982; Pereira Filho et al., 1998; Pereira Filho et al., 2018) - trata-se de um sistema de análise objetiva para integrar estimativas de precipitação diária com satélite (CST) com as medidas de precipitação com a rede telemétrica da CESP; os pesos atribuídos às estimativas e medições são dados pelas estatísticas de erros destas no espaço; pode-se, por meio desse método, determinar a erro esperado nas análises; 6) operacionalização SPH (Sistema de Previsão Hidrometeorológica) (Pereira Filho et al., 1998; Pereira Filho et al., 2005) - Compreende um sistema de processamento, análise, disseminação e armazenamento de dados na formatação apropriada para entrada no modelo SMAP da CESP; 7) modelagem com o modelo hidrológico SMAP - trata-se de um modelo hidrológico compacto para previsão de vazão a partir de dados diários de precipitação medida, estimada e prevista com tempo de antecedência de até 15 dias; os dados de precipitação medidos no dia anterior e os previstos, subsequentemente, são utilizados na previsão de vazão.

Considerando que o SMAP foi implantado na CESP em novembro de 2011, as previsões e as análises da pre- 
cipitação média diária foram realizadas para o período a partir de novembro de 2011 até 2015. Houve necessidade de se calibrar o modelo SMAP com as estimativas de ARPS e CST (além do CMOPRH, não apresentado neste manuscrito) para cada uma das sub-bacias. Essa calibração foi feita com a otimização dos parâmetros do SMAP, que são intrínsecos à determinada sub-bacia, mediante $\mathrm{o}$ emprego de fontes de dados combinadas entre 2011 e 2013. Assim, as rodadas do SMAP entre 2011 e 2013 tiveram como objetivo avaliar o comportamento de cada modelo de previsão de precipitação, já que havia disponibilidade de valores de vazão verificada nas subbacias, que puderam ser comparados com as vazões calculadas pelo SMAP nessas sub-bacias. A previsão de vazão foi iniciada a partir de 01 de janeiro de 2015. As previsões de vazão foram confrontadas com os dados de vazão observada, o que contribuiu para a avaliação do SMAP com a base de dados completa. Todas as metodologias desenvolvidas foram analisadas para verificação de desempenho de forma independente a partir da rede telemétrica da CESP e da calibração e verificação do modelo hidrológico SMAP. Assim, o projeto desenvolveu seis técnicas de estimativa (CST, Thiessen, ANOBES e CMORPH) e previsão (ARPS e GFS) de precipitação média diária para um horizonte de até quinze dias à frente. Foram utilizadas bases de dados com alta resolução espaço-temporal integradas aos dados da rede telemétrica da CESP. A seguir, apresenta-se uma síntese de módulos específicos destacados neste manuscrito.

\subsection{Sistema integrado de previsão da CESP}

A melhoria na estimativa de precipitação tem sido desenvolvida internacionalmente por meio da inclusão de informações de redes de pluviômetros, radares e satélites, com técnicas avançadas de integração. Por exemplo, Crawford (1988) e Pereira Filho et al. (1998) mostraram que é necessária uma rede extremamente densa para obter acuradamente a estimativa de precipitação nas escalas regionais e locais, ou seja, quando a precipitação é derivada de fenômenos como tempestades isoladas e linhas de instabilidade. Uma vez que a instalação de uma rede muito densa representa um desafio, utilizaram dados de radar meteorológico para melhorar a resolução espacial. Chunyan e Krajewski (1996) mostraram a importância da correção dos dados de radar meteorológico por meio de uma rede de pluviômetros e importância da integração das informações. A técnica de Análise Objetiva Estatística ANOBES foi utilizada com sucesso em Oklahoma, EEUU (Pereira Filho et al., 1998) e em São Paulo (Pereira Filho, 1999). A técnica utiliza dados de radar meteorológico e de uma rede de pluviômetros. Adler e Negri (1988) desenvolveram uma técnica chamada CST (Convective-Stratiform Technique), que utiliza a temperatura de brilho (temperatura obtida pela irradiância das nuvens medidas pelo satélite) para converter em precipitação utilizando a iden- tificação de dois padrões de sistemas meteorológicos convectivo ou estratiforme. Essa técnica foi calibrada para o Brasil (Negri et al., 2002) por ocasião de um experimento na Amazônia durante a estação chuvosa de 1999. Xue et al. (2000) desenvolveram um modelo numérico de previsão de tempo com o objetivo de realizar previsões em escalas regionais e locais, ou seja, prognosticar fenômenos como tempestades isoladas, linhas de instabilidade e eventos que provocam intensas precipitações e fortes rajadas de vento. A capacidade de previsão quantitativa mostra-se satisfatória, mas é fundamental que sejam introduzidas informações suficientes do estado atual da atmosfera, ou seja, de assimilação de dados que representem esse estado. Por essa razão, a assimilação de dados é fundamental e provoca impactos significativos na previsão quantitativa de precipitação. Apresentam-se, a seguir, os sistemas de medição utilizados, métodos de análise e previsão meteorológica e hidrológica com o sistema ARPS e o modelo SMAP, respectivamente.

\subsection{Rede telemétrica da CESP}

De modo a ter um monitoramento e controle da disponibilidade hídrica nas regiões de seus reservatórios (Fig. 1), a CESP instalou e mantém em operação uma rede de estações hidrométricas nas áreas a montante e a jusante das usinas de Ilha Solteira, Eng. Souza Dias (Jupiá) e Eng. Sérgio Motta (Porto Primavera) na região hidrográfica do Paraná e nas regiões a montante e jusante das usinas Paraibuna e Jaguari na região hidrográfica do Paraíba do Sul. Essa rede telemétrica está em conformidade com o que preconiza a Resolução Conjunta $\mathrm{N}^{\mathrm{o}} 3$ ANEEL/ANA de 10/08/2010 quanto à quantidade de postos instalados bem como os tipos de monitoramento realizados. As informações de nível dos rios são obtidas pelas estações através de sensores de nível hidrostático, e as informações de precipitação são obtidas pelos pluviômetros, que contam com sistema de básculas que converte o volume de água precipitado em sinal eletrônico. A aquisição dos dados de nível e de precipitação são computados e enviados hora a hora através de um sistema de telemetria para um banco de dados denominado Sistema de Geração e Hidrologia Integrado à Medição (SGHim). Esses dados são utilizados para planejamento da operação das usinas e também para estudos de hidrologia. Uma maior relevância expressa-se neste projeto de pesquisa quanto aos monitoramentos pluviométricos e fluviométricos, uma vez que estes são os que revelam a disponibilidade de água que poderá ser utilizada nos reservatórios para a produção de energia. Dessa forma, a CESP conta com um determinado número de estações fluviométricas para cada um dos seus reservatórios, conforme exposto a seguir.

No reservatório da UHE Ilha Solteira, tem-se as estações: 1) Fazenda Mumbela - instalada no rio Corrente, afluente do rio Paranaíba pela margem direita, a montante da confluência com o rio Grande, onde se forma o rio 
Paraná, localizada no município de Caçu-MS; até esse local, a área de drenagem é da ordem de $7.700 \mathrm{~km}^{2}$, o que corresponde a um monitoramento de $11,9 \%$ da área de drenagem incremental da UHE; 2) Fazenda Bálsamo instalada no rio Aporé, afluente do rio Paranaíba pela margem direita, a montante da confluência com o rio Grande, onde se forma o rio Paraná, com localização no município de Itajá-MS; até esse local, a área de drenagem é da ordem de $7.090 \mathrm{~km}^{2}$, o que corresponde a um monitoramento de $11,0 \%$ da área de drenagem incremental da UHE; 3) Ponte São Domingos - instalada no rio São Domingos, afluente do rio Paraná pela margem esquerda, a jusante da confluência com o rio Grande, situada no município de Limeira D' Oeste-MG; até esse local, a área de drenagem é da ordem de $3.520 \mathrm{~km}^{2}$, o que corresponde a um monitoramento de $5,5 \%$ da área de drenagem incremental da UHE; 4) Fazenda Palmeirinha - instalada no rio São José dos Dourados, afluente do rio Paraná pela margem esquerda, a jusante da confluência com o rio Grande, localizada no município de Auriflama-SP; até esse local, a área de drenagem é da ordem de $3.364 \mathrm{~km}^{2}$, o que corresponde a um monitoramento de 5,2\% da área de drenagem incremental da UHE.

O restante do monitoramento é realizado por meio da verificação das vazões defluentes das usinas de Água Vermelha, São Simão, Foz do Rio Claro e Salto do Rio Verdinho. O reservatório da UHE Eng. Souza Dias (Jupiá) está localizado logo a jusante da UHE Ilha Solteira, na cascata do rio Paraná, e o seu único contribuinte significativo é o rio Sucuriú, afluente pela margem direita do rio Paraná. No rio Sucuriú, a CESP opera a estação denominada Fazenda São Sebastião, localizada no município de Três Lagoas - MS. Até o local da estação, a área de drenagem é da ordem de $12.481 \mathrm{~km}^{2}$, o que representa $50,7 \%$ da área de drenagem incremental nesse trecho. Assim, o restante do monitoramento é realizado pela verificação das vazões defluentes das UHE Três Irmãos e UHE Ilha Solteira localizadas a montante. Há, ainda, instalada a estação Jupiá localizada a jusante no rio Paraná no município de Três Lagoas - MS. Até esse local, a área de drenagem é da ordem de $470.000 \mathrm{~km}^{2}$. A estação é utilizada para controle das vazões defluentes da UHE Eng. Souza Dias (Jupiá), no entanto a mesma sofre a influência do remanso formado pelo lago da UHE Sérgio Motta (Porto Primavera) quando o mesmo atinge determinados níveis operativos.

O reservatório da UHE Eng. Sérgio Motta (Porto Primavera) dispõe das seguintes estações telemétricas: 1) Porto Velho - instalada no rio Verde, afluente do rio Paraná pela margem direita, localizada no município de Três Lagoas - MS; até esse local, a área de drenagem é da ordem de $21.800 \mathrm{~km}^{2}$, o que corresponde a um monitoramento de $20,96 \%$ da área de drenagem incremental da UHE; 2) Fazenda Buriti - instalada no rio Pardo, afluente do rio Paraná pela margem direita, localizada no municí- pio de Bataguassu - MS; até esse local, a área de drenagem é da ordem de $31.500 \mathrm{~km}^{2}$ o que corresponde a um monitoramento de $30,29 \%$ da área de drenagem incremental da UHE; 3) Flórida Paulista - instalada no rio do Peixe, afluente do rio Paraná pela margem esquerda, localizada no município de Flórida Paulista; até esse local, a área de drenagem é da ordem de $6.780 \mathrm{~km}^{2}$, o que corresponde a um monitoramento de $6,51 \%$ da área de drenagem incremental da UHE; 4) Salto Carlos Botelho - instalada no rio Aguapeí, afluente do rio Paraná pela margem esquerda, está localizada no município de Lucélia - SP; até esse local, a área de drenagem é da ordem de $7.800 \mathrm{~km}^{2}$, o que corresponde a um monitoramento de 7,5\% da área de drenagem incremental da UHE; 5) Porto Primavera jusante instalada no rio Paraná, a jusante da UHE Eng. Sérgio Motta (Porto Primavera), localizada no município de Rosana - SP; até esse local a área de drenagem é da ordem de $574.000 \mathrm{~km}^{2}$. Essa estação é para controle e verificação das vazões defluentes da UHE Eng. Sérgio Motta (Porto Primavera).

Com enfoque nas usinas localizadas na região hidrográfica do Paraíba do Sul, as estações que monitoram o reservatório da UHE Jaguari são: 1) Cachoeira do Jaguaribe - instalada no rio Jaguari, afluente do rio Paraíba do Sul pela margem esquerda (encerra-se no reservatório da UHE Jaguari), localizada no município de Santa Isabel - SP; até esse local, a área de drenagem é da ordem de $350 \mathrm{~km}^{2} \mathrm{o}$ que corresponde a um monitoramento de $26,9 \%$ da área de drenagem incremental da UHE; 2) Fazenda Santana instalada no rio do Peixe, afluente do rio Paraíba do Sul pela margem esquerda (encerra-se no reservatório da UHE Jaguari), localizada no município de São Francisco Xavier - SP; até esse local, a área de drenagem é da ordem de $456 \mathrm{~km}^{2}$, o que corresponde a um monitoramento de $35,1 \%$ da área de drenagem incremental da UHE; 3 ) Jaguari Jusante - instalada no rio Jaguari, afluente do rio Paraíba do Sul pela margem esquerda a estação, localizada a jusante da UHE Jaguari no município de São José dos Campos. Nesse local, a área de drenagem é da ordem de $1.300 \mathrm{~km}^{2}$; essa estação é para controle e verificação das vazões defluentes da UHE Jaguari.

Complementarmente, as estações que monitoram o reservatório da UHE Paraibuna são: 1) Fazenda Palmeiras - instalada no rio Paraibuna, um dos formadores do rio Paraíba do Sul (encerra-se no reservatório da UHE Paraibuna), localizada no município de Natividade da Serra SP; até esse local, a área de drenagem é da ordem de $540 \mathrm{~km}^{2}$, o que corresponde a um monitoramento de $12,0 \%$ da área de drenagem incremental da UHE; 2) São Luiz do Paraitinga - instalada no rio Paraitinga, um dos formadores do rio Paraíba do Sul (encerra-se no reservatório da UHE Paraibuna), localizada no município de São Luiz do Paraitinga - SP; até esse local, a área de drenagem é da ordem de $1.920 \mathrm{~km}^{2}$, o que corresponde a um monitoramento de $42,7 \%$ da área de drenagem incremental da 
UHE; 3) Paraibuna jusante - instalada no rio Paraibuna, um dos formadores do rio Paraíba do Sul pela margem esquerda, localizada a jusante da UHE Paraibuna no município de Paraibuna - SP; nesse local, a área de drenagem é da ordem de $4.500 \mathrm{~km}^{2}$; Essa estação é para controle e verificação das vazões defluentes da UHE Paraibuna.

\subsection{Estimativa de chuva por satélite nas bacias dos rios Paraná e Paraíba do Sul}

A estimativa de precipitação é realizada por meio de canais de infravermelho (IR) e vapor d'água (WV) do satélite meteorológico METEOSAT segunda geração (MSG) com a técnica CST (Convective-Stratiform Techni$q u e$ ). As imagens MSG são processadas com resolução temporal de quinze minutos em doze canais, que permitem estudos de nuvens por meio da radiação eletromagnética emitida na região do espectro visível e infravermelho. A alta disponibilidade de imagens é imprescindível para o monitoramento contínuo das condições atmosféricas em tempo real e fornece subsídios para o desenvolvimento da técnica CST aplicada para estimativa da precipitação, além do diagnóstico do comportamento da atmosfera em curto prazo. A Fig. 3 mostra um exemplo de imagem do satélite nos canais visível (VIS), infravermelho (IR) e vapor de água (WV) sobre a região de interesse.

O canal visível é utilizado para a detecção, monitoramento e classificação de nuvens durante o dia, por meio da análise de textura e refletância. No espectro infravermelho, janelas atmosféricas permitem inferência da temperatura de brilho, detecção de nuvens cirrus não precipitantes e, em conjunto com os canais no visível, auxiliam a discriminação entre nuvens constituídas predominantemente por partículas de água ou gelo. Os canais de vapor de água são destinados à observação da distribuição de vapor de água na atmosfera, sendo que o pico de banda dos canais disponíveis permite monitorar médios e altos níveis da troposfera. A variedade de canais possibilita pesquisa para determinação do conjunto ideal de canais necessário para aperfeiçoar a estimativa da precipitação sobre a bacia hidrográfica do Paraná. A Fig. 4 ilustra imagens obtidas a cada 1 hora no canal IR $(10,8 \mu \mathrm{m})$ sobre a região de interesse.

\subsection{Estimativa de precipitação com a técnica CST}

A técnica CST (Convective - Stratiform Technique) foi desenvolvida por Adler e Negri (1988) e aprimorada por Negri et al. (2002) para a bacia Amazônica. A técnica foi aplicada para a região de cobertura do radar operacional de São Paulo. Desenvolveu-se uma metodologia de comparação com dados de radar e pluviômetro que aperfeiçoaram a estimativa da precipitação com propósitos de aplicação à gestão de recursos hídricos. Os dados disponíveis do canal IR $(10,8 \mu \mathrm{m})$ do MSG serão utilizados para calibração da técnica CST para a região da bacia hidro- gráfica do Paraná. As amostras obtidas pelas imagens de satélite a cada 15 minutos têm resolução espacial de aproximadamente $4,8 \mathrm{~km} \times 4,8 \mathrm{~km}$ por píxel, cobrindo uma área de aproximadamente $760 \mathrm{~km}^{2}$, cuja bacia hidrográfica está inserida no centro da região, conforme Fig. 3. Diariamente, são disponibilizadas 96 imagens obtidas pelo satélite meteorológico MSG.

Resumidamente, a técnica CST identifica a menor temperatura de brilho sobre a região de interesse e filtra as nuvens não precipitantes. Essas regiões são denominadas centros de convecção. Limiares são definidos para cada tipo de precipitação, convectiva ou estratiforme, e, então, a temperatura de brilho é convertida em campos de taxa de precipitação em $\mathrm{mm} \mathrm{h}^{-1}$, que podem ser assimilados por modelos hidrológicos. Os campos de precipitação estimados pela técnica CST serão integrados com dados obtidos pela rede telemétrica por meio da técnica de Análise Objetiva Estatística (ANOBES), produzindo uma estimativa integrada da precipitação em que se minimizam as deficiências inerentes a cada sistema de medição.

\subsection{Análise objetiva estatística (ANOBES)}

Muitas técnicas de análise objetiva têm sido propostas para caracterizar padrões de chuva e para avaliar a média da chuva sobre uma bacia. Algumas são mais simples, outras mais complexas. A análise objetiva estatística é indicada como uma boa técnica de interpolação para campos meteorológicos e é reconhecida pela Organização Mundial de Meteorologia (OMM). Esta metodologia foi aplicada com êxito para analisar campos de precipitações totais (Pereira Filho et al., 1998). A técnica de análise objetiva estatística foi utilizada por Pereira Filho et al. (1998) para reduzir erros observacionais e, assim, melhorar os resultados de previsões hidrológicas. Eles utilizaram uma estrutura de covariância do erro isotrópica para uma rede de medição de precipitação de alta densidade em latitudes médias, onde a componente anisotrópica da covariância do erro pode ser negligenciada, embora os sistemas de precipitação geralmente não sejam circulares e provavelmente têm uma estrutura anisotrópica. A anisotropia da função de covariância constitui uma significativa fonte de erros nos esquemas de interpolação em locais com poucos dados ou configurações irregulares de estações (Pereira Filho et al., 1998). A técnica de análise objetiva estatística proposta por Pereira Filho et al. (1998) será utilizada, neste trabalho, com dados de estimativa de precipitação por satélite e por meio da rede telemétrica de pluviômetros existentes nas bacias da CESP. Matematicamente, a técnica de análise objetiva proposta pode ser escrita como

$$
P_{a}\left(x_{i}, y_{i}\right)=P_{r}\left(x_{i}, y_{i}\right)+\sum_{k=1}^{K} w_{i k}\left[P_{g}\left(x_{k}, y_{k}\right)-P_{r}\left(x_{k}, y_{k}\right)\right]
$$

onde $P_{a}\left(x_{i}, y_{i}\right)$ - precipitação analisada; $P_{r}\left(x_{i}, y_{i}\right)$ - estimativa da precipitação do satélite; $P_{g}\left(x_{k}, y_{k}\right)$ - medidas plu- 


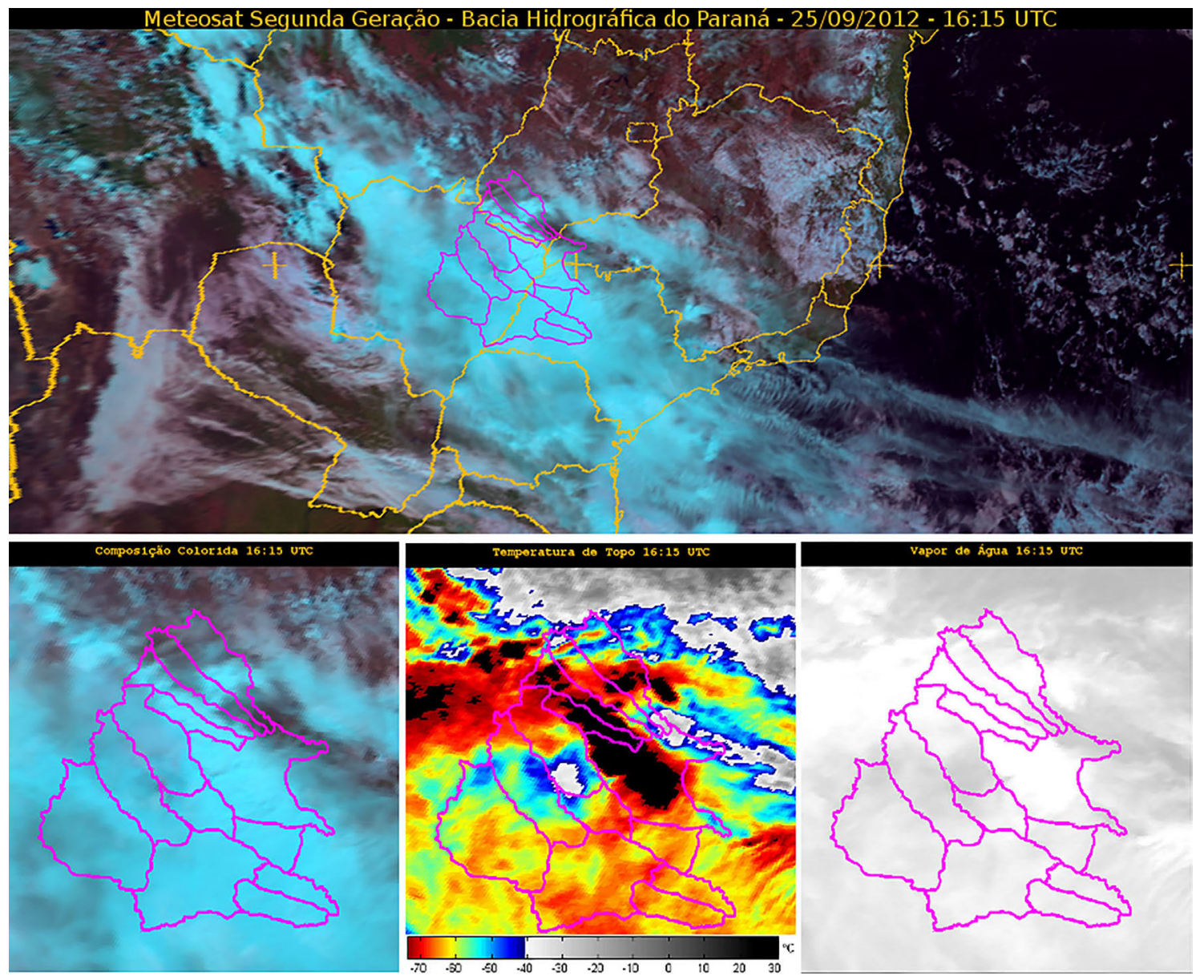

Figura 3 - Imagens do Meteosat segunda geração obtidas às 16:15 UTC de 25/09/2012. Na parte superior visão geral das nuvens sobre regiões centrooeste, sudeste e sul do Brasil. A bacia hidrográfica do Paraná está indicada em magenta. Na parte inferior, da esquerda para direita: composição colorida (visível), canal infravermelho termal (IR) e canal de vapor de água (WV). A temperatura do topo das nuvens é indicada pela barra de cores. Estão indicados os contornos geopolíticos. Fonte: EUMETSAT.

viométricas de precipitação; $\left(x_{i}, y_{i}\right)$ - localização do pixel do satélite; $\left(x_{k}, y_{k}\right)$ - localização do pluviômetro; $K$ número de pluviômetros; $w_{\mathrm{k}}$ - peso a posteriori:

$$
\sum_{l=1}^{K} W_{l}\left[\rho_{k l}+\varepsilon_{k}^{2}\right]=\rho_{k i}
$$

onde $\rho_{k l}$ - correlação do erro entre os locais $k$ e $l ; \rho_{k i}$ - correlação do erro entre os locais $k$ e $i$ do pluviômetro e do píxel do satélite; $\varepsilon_{k}^{2}$ - erro normalizado da observação; $W_{l}$ peso a posteriori com $1 \leq k \leq K$.

As estimativas de precipitações acumuladas pelo radar serão utilizadas para estimar a correlação de erros. O modelo de correlação do erro da chuva acumulada será estimado em função da distância e da direção entre os píxeis de satélite com precipitação acumulada diária. A variância do erro esperado da análise (NEXERVA) é dada por:

$$
\varepsilon_{a}^{2}=1-\sum_{l=1}^{K} \rho_{k i} W_{l}
$$

O NEXERVA é a razão entre a variância do erro esperado da análise e variância do erro do campo inicial de precipitação. Pode ser usado para estimar a distribuição especial do erro da análise e a redução global de erros para um dado intervalo de acumulação de chuva. Em geral, quanto mais próxima a análise do ponto de medição de chuva com a rede de pluviômetros, menor o erro da análise. A correlação cruzada do erro do campo inicial de chuva é o componente mais importante do método ANOBES, dado por Pereira Filho et al., (1998) como

$$
\rho_{k l}=\frac{\left\langle\left(P_{r}^{k}-P_{t}^{k}\right)\left(P_{r}^{l}-P_{t}^{l}\right)\right\rangle}{\sqrt{\left\langle\left(P_{r}^{k}-P_{t}^{k}\right)^{2}\right\rangle\left\langle\left(P_{r}^{l}-P_{t}^{l}\right)^{2}\right\rangle}}
$$

onde $P_{r}^{k(l)}$ é a precipitação acumulada estimada do satélite $(\mathrm{mm})$ nos pontos $k(l)$. Desde que o volume de precipi- 
tação real $P_{t}^{k(l)}$ não é conhecido, $\rho_{k l}$ é estimado com suporte de séries de dados, por meio da substituição de $P_{t}$ pela precipitação média de longo termo ou precipitação ao longo do tempo total da série utilizada para estimar acumulações em intervalos de 24 h. A Fig. 5 mostra um exemplo de integração do campo de precipitação diária

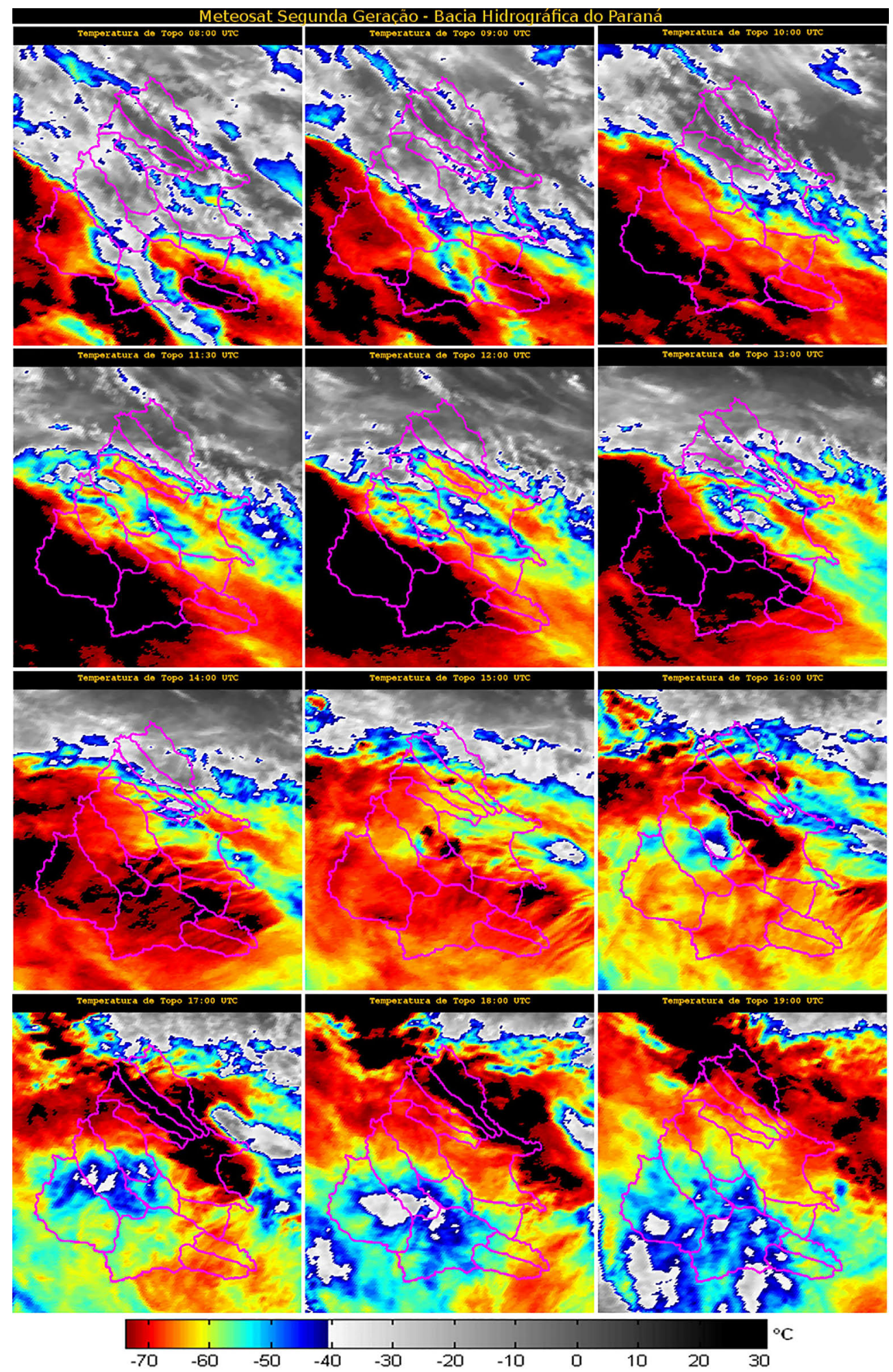

Figura 4 - Imagens do canal IR (10,8 $\mu \mathrm{m})$ obtidas entre 08:00 UTC e 19:00 UTC de 25/09/2012. A temperatura do topo das nuvens é indicada pela barra de cores. Os contornos das bacias hidrográficas da CESP no rio Paraná estão destacados em magenta. Fonte: EUMETSAT. 


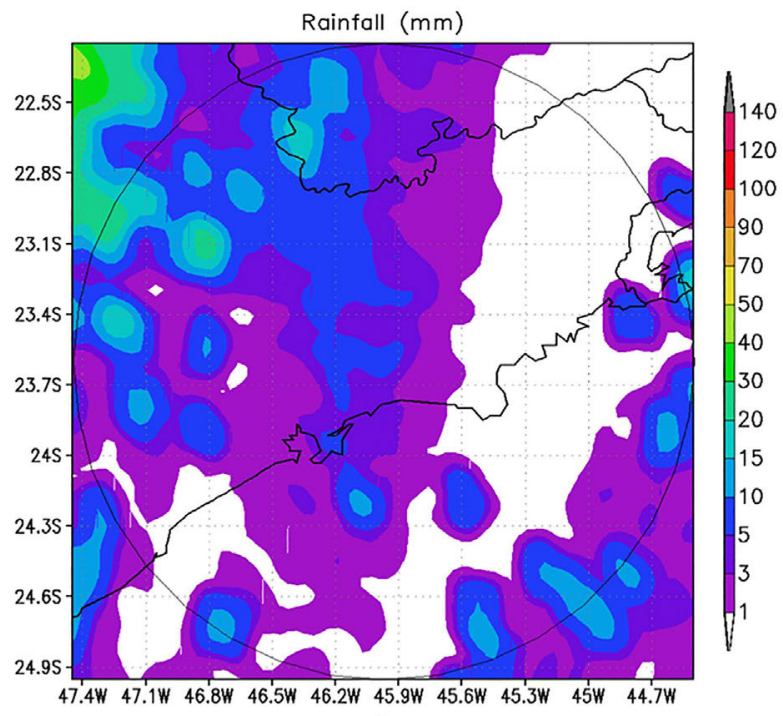

(A)

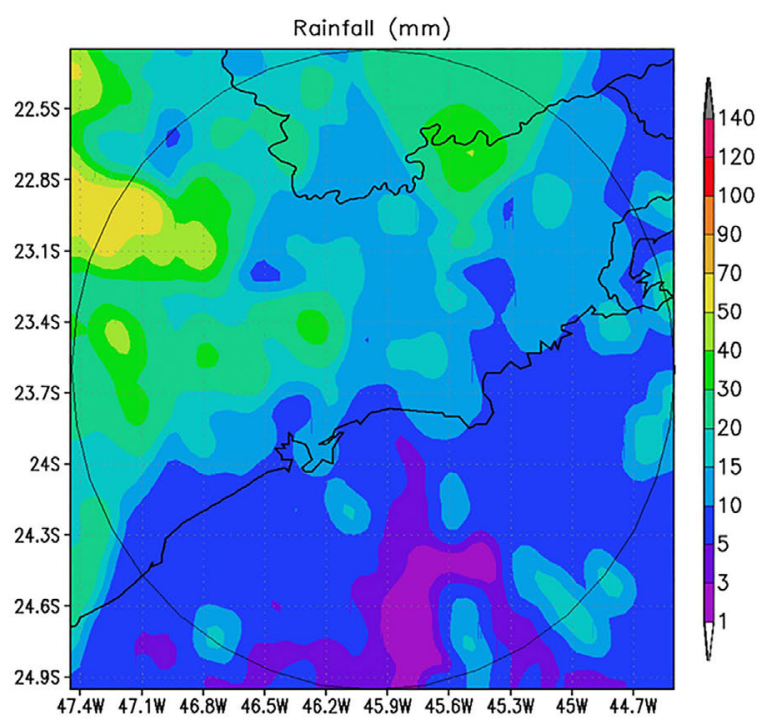

(B)

Figura 5 - Precipitação acumulada diária estimada em 14/01/2002 com a técnica CST (esquerda) e integração com a rede de superfície (direita) com análise de três pontos para as datas indicadas. Escala de cores indica precipitação acumulada (mm). Latitudes e longitudes estão indicadas no mapa. Fonte: Pereira Filho (2004).

estimado com a técnica CST integrada a rede de pluviômetros na área de cobertura do radar de São Paulo (Pereira Filho, 2004). Nota-se uma sensível diferença entre o campo original de precipitação estimada por satélite e depois da análise objetiva.

A compreensão adequada do impacto da precipitação ou ausência dela em uma bacia hidrográfica está intimamente ligada à qualidade e à cobertura espacial e temporal dos dados de precipitação. Métodos de estimativa, como radar e satélite, e observações de superfície possuem erros individuais, que podem causar tendência nas análises. Assim, o método de interpolação de dados de diferentes fontes surge como solução para redução dos erros associados a cada método isoladamente. As estimativas de precipitação por satélite (CST) foram utilizadas para integração com dados pluviométricos enviados pela CESP via técnica ANOBES. Com a aplicação do ANOBES, foi possível criar um novo campo de precipitação melhorado e com erros reduzidos. Um evento de precipitação associada a uma frente fria foi utilizado para teste do ANOBES com três postos mais próximos de cada pixel de análise. A taxa de precipitação estimada pelo CST subestimou a observada nos postos em cerca de $50 \%$. Com a aplicação do ANOBES, a área em torno do posto teve a precipitação aprimorada, no entanto áreas fora da cobertura do raio de influência dos postos permaneceram praticamente inalteradas. $\mathrm{O}$ número de postos utilizados na integração afetou significativamente o resultado da ANOBES. Uma distribuição de postos pluviométricos com maior densidade de pontos em maior cobertura espacial e melhora no campo final de chuva. O setor oeste da bacia do Paraná foi a mais afetada pela ausência de postos pluviométricos. Portanto, a integração das informações da estimativa de precipitação na bacia do rio Grande foi desenvolvida a partir da adaptação de algoritmos para a integração das informações de redes telemétricas automáticas hidrometeorológicas da CESP, ANA e DAEE, e satélite geoestacionário MSG para melhorar a estimativa de precipitação na região das bacias hidrográficas da CESP.

\subsection{Sistema ARPS}

O modelo numérico ARPS foi utilizado para previsão de chuva com até cinco dias de antecedência para as bacias da CESP na região indicada na Fig. 6. As principais características do modelo ARPS (Xue et al., 2000) são: 1) equações compressíveis e não hidrostáticas da atmosfera; geometria cartesiana $3 \mathrm{D}$ e coordenada vertical $\sigma_{\mathrm{z}}$ (segue as variações do terreno), com opção de resolução vertical indicada pelo usuário; 2) advecção de segunda e quarta ordem quadraticamente conservativa na grade tipo $\mathrm{C}$ de Arakawa; 3) esquema Runge Kutta de terceira ordem e "leapfrog" semiexplícito para os modos de gravidade e acústicos, respectivamente, com opção para filtro de Asselin; 4) iniciação analítica, homogênea com sondagem e heterogênea tridimensional; 5) condições laterais rígidas, gradiente zero, periódicas, radiativa, forçadas externamente por nudging e especificadas pelo usuário; 6) translação automática de domínio aninhado para seguir trajetórias de tempestades (storm-tracking); 7) parametrização de microfísica de Kessler (warm-rain) (Keesler, 1969) e 3 categorias de gelo, num total de 6 fases de 


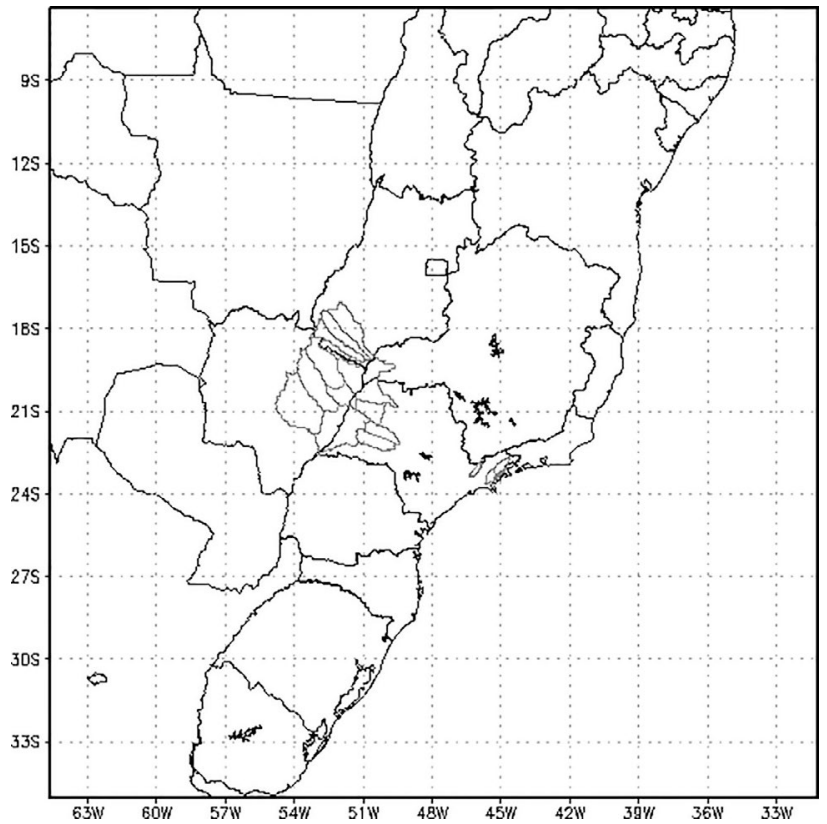

Figura 6 - Área com o domínio das simulações com o modelo numérico ARPS. Contorno em preto indica limites geopolíticos e o contorno em vermelho indica a delimitação das sub-bacias hidrográficas de interesse.

água: água de nuvem, água de chuva, gelo de nuvem, granizo, granizo leve (graupel); 8) parametrização de cúmulos de Kain-Fritsch e Kuo; 9) parametrização de fluxos de calor, umidade e momento a partir das leis de arrasto aerodinâmico, com formulações dependentes da estabilidade atmosférica; 10) modelo de solo difusivo com múltiplas camadas e opção de inicialização usando o índice de precipitação antecedente; 11) iniciação do modelo em tempo real por meio de condições iniciais geradas pelo pacote de análise objetiva local; 12) assimilação de dados tridimensionais (3DVAR) para vários tipos de conjunto de dados, entre eles coordenadas esféricas de radar Doppler.

O modelo ARPS é executado num cluster com as seguintes características: 1) 2 processadores Intel Xeon Eight-Core de $2.9 \mathrm{GHZ}$, com 8 núcleos cada um (total de 16 cores) e $20 \mathrm{MB}$ de memória CACHE, $8 \mathrm{GT} / \mathrm{s}$; 2) 128 GB de memória DDR3 $1600 \mathrm{MHz}$; 3) 2 discos de 3TB SATA2; 4) 4 ports Gigabit Ethernet; 5) 1 port Infiniband QDR 4x; 6) Fontes redundantes; 7) Linux debian squeeze, com pacotes Libjpeg, LibZ, LibJasper, Libnetcdf, LibHDF, entre outras bibliotecas necessárias para o pacote ARPS. A assimilação das análises advém do modelo global GFS (Global Forecast System), operado pela NOAA. O sistema contém dados de temperatura, umidade, direção e intensidade do vento em escala global de baixa resolução espacial e resolução temporal de 3 horas, que alimenta a grade inicial do modelo numérico ARPS. As variáveis de interesse são os componentes zonal, meridional e vertical do vento, umidade relativa, temperatura do ar, entre outras variáveis, que permitem calcular a precipitação acumulada para os dias seguintes. As variáveis disponibilizadas pelo GFS são utilizadas como condição inicial e de fronteira nas simulações de alta resolução espacial ARPS para até 5 dias a frente. O modelo numérico ARPS aumenta a resolução espacial para $12 \mathrm{~km}$ e temporal para 1 hora com previsão de precipitação, temperatura e umidade entre outras variáveis sobre a bacia de interesse. O prognóstico de chuva do sexto ao décimo quinto dia baseia-se no modelo global GFS. O modelo ARPS é executado duas vezes ao dia às 00:00 UTC e às 12:00 UTC com as respectivas bacias de interesse delimitadas. A avaliação das estimativas obtidas com a modelagem é obtida por meio da correlação ponto a ponto entre as diferentes estimativas de precipitação e das tabelas de contingência dos índices estatísticos CSI (índice de sucesso crítico), POD (probabilidade de detecção), FAR (falso alarme) e BIAS (viés) sobre a região das bacias de interesse de acordo com a Tabela 1.

Os índices estatísticos (CSI, POD, FAR e BIAS) são funções do número total de acertos, erros e falsos alarmes e são calculados mediante o seguinte conjunto de equações (Donaldson et al., 1975).

$$
\begin{gathered}
\text { Indice } C S I=\frac{\text { acertos }}{\text { acertos }+ \text { erros }+ \text { falsos alarmes }} \\
\text { Indice POD }=\frac{\text { acertos }}{\text { acertos }+ \text { erros }} \\
\text { Indice FAR }=\frac{\text { acertos }}{\text { acertos }+ \text { falsos alarmes }} \\
\text { Indice BIAS }=\frac{\text { total acertos }+ \text { total falsos alarmes }}{\text { total acertos }+ \text { total erros }}
\end{gathered}
$$

A avaliação por meio desses índices é limitada, pois avalia-se cada ponto de grade. Se houver um deslocamento da chuva para algo em torno de 1 hora ou 1 pixel para o lado, esse conjunto de índices estatísticos considera o ponto como errado, quando, na verdade, o mesmo está na mesma sub-bacia. Além disso, consideram-se apenas os pontos de grade com chuva e são descartados os pontos de grade sem chuva. Desse modo, para o caso de não haver chuva em qualquer ponto de grade em ambos ARPS e CMORPH,

Tabela 1 - Condições para píxeis com acerto, erro, falso alarme e abaixo do limite.

\begin{tabular}{lcc}
\hline & ARPS & CMORPH \\
\hline Acerto & $\mathrm{P}>0,5$ & $\mathrm{P}>0,5$ \\
Erro & $\mathrm{P}<0,5$ & $\mathrm{P}>0,5$ \\
Falso Alarme & $\mathrm{P}>0,5$ & $\mathrm{P}<0,5$ \\
Abaixo do limite & $\mathrm{P}<0,5$ & $\mathrm{P}<0,5$ \\
\hline
\end{tabular}


não será considerado $100 \%$ de acerto, e a grade correspondente a essa situação será descartada.

\subsection{Modelo SMAP}

O modelo "Soil Moisture Accounting Procedure" ou SMAP é um modelo determinístico de simulação hidrológica do tipo transformação chuva-vazão. Foi desenvolvido, em 1981, por Lopes et al. (1982), e apresentado no "International Symposium on Rainfall-Runoff Modeling" realizado em Mississippi, U.S.A. e publicado por Lopes et al. (1982). O desenvolvimento do modelo baseou-se na experiência com a aplicação do modelo "Stanford Watershed IV" e modelo Mero em trabalhos realizados no DAEE- Departamento de Águas e Energia Elétrica do Estado de São Paulo. Foi originalmente desenvolvido para intervalo de tempo diário. Posteriormente, foram apresentadas versões horária e mensal, implementando-se algumas modificações em sua estrutura (Lopes e Porto, 1991). O modelo de simulação hidrológica SMAP tem sido utilizado por diversas entidades que necessitam quantificar as vazões em bacias hidrográficas a partir de dados de precipitação e evaporação. Além da CESP - Companhia Energética de São Paulo, pode-se citar as seguintes empresas que também utilizam o modelo SMAP em previsões de vazões: Operador Nacional do Sistema Elétrico Nacional (ONS), Companhia de Saneamento Básico do Estado de São Paulo (SABESP), Duke Energy, entre outras. O sistema chuva-vazão SMAP foi implantado na CESP em novembro de 2011 e teve como objetivo principal realizar previsões de vazões incrementais horárias aos reservatórios a partir das chuvas previstas nas sub-bacias do sistema. Essas previsões de vazões servem de subsídios para a realização do programa diário de geração e de defluências dos aproveitamentos operados pela CESP. No presente trabalho, foram utilizadas as estimativas de precipitação ocorridas nas bacias da CESP fornecidas pelo modelo ARPS, CST e ANOBES desenvolvidos pelo IAG para serem aplicadas ao modelo SMAP. Entretanto, para melhor confrontar as diversas estimativas de precipitação foram usadas, para cada sub-bacia, os mesmos parâmetros característicos do modelo SMAP. Os cálculos da precipitação acumulada em totais diários foram obtidos para cada região das bacias hidrográficas, em horário local. A identificação das regiões em cada bacia hidrográfica permite a estimativa de precipitação em pequenas áreas. Os píxeis correspondentes às regiões estão identificados na imagem de satélite com um arquivo KML para extração de pontos referentes às feições das regiões e sobreposição à divisão político-administrativa com divisas territoriais referentes às regiões. Cada região dispõe de postos pluviométricos utilizados na estimativa de precipitação integrada por satélite e pluviômetros e utilização da técnica ANOBES. As coordenadas geográficas foram obtidas a partir da identificação de pontos que definem os polígonos referentes a cada região identificada. O QUANTUM GIS foi utilizado para leitura do arquivo KML, para identificar as regiões e para obter os pontos. Por se tratar de um arquivo vetorial, os polígonos delimitados no KML possuem geometria definida por um par de coordenadas, que determinam um vetor. Por outro lado, as imagens de satélite são arquivos matriciais (formato RASTER) em que polígonos são definidos como um conjunto de coordenadas geográficas referentes a uma matriz de píxeis com espaçamento adequado à resolução da imagem. Para representação das feições nas imagens de satélite, obtevese, a partir da informação vetorial, os pontos da matriz correspondente. As coordenadas referentes às regiões foram delimitadas por meio da interpolação de pontos das coordenadas que definem os polígonos das sub-bacias por meio da densificação da geometria do KML. Dessa forma, foram realizadas as previsões de vazões para as bacias com o modelo SMAP utilizando os dados de precipitações ocorridas nas bacias, estimados pelos modelos ARPS, CST, ANOBES e CMORPH (Pereira Filho et al., 2018). Essas previsões de vazões foram confrontadas com aquelas vazões observadas nas respectivas bacias.

\subsection{Sistema automático operacional}

A previsão quantitativa de precipitação $(\mathrm{PQP})$ nas bacias hidrográficas da CESP foram automatizadas. São ajustadas as parametrizações e as inserções de informações da rede integrada de precipitação no modelo numérico de previsão de tempo. O algoritmo com execução automática foi desenvolvido para estimar a precipitação média diária com até quinze dias de antecedência nas bacias hidrográficas mostradas na Fig. 1. Um esquema de agrupamento é utilizado no cálculo do desvio padrão da chuva prevista, que é maior para chuvas convectivas e menores para chuvas estratiformes. A rede de estações de superfície é utilizada para ajuste e calibração do modelo ARPS, e progressiva melhoria no método de estimativa de chuva. Além disso, a chuva medida pela rede de estações em superfície é usada na calibração dos métodos de estimativa de precipitação com melhora na quantificação da chuva. Além desta, utiliza-se a estimativa do método CMORPH (Fig. 6). Ressalta-se que a estimativa CMORPH é obtida depois de 36 horas. O método de estimativa será baseado nos dados do satélite METEOSAT recebidos a cada 15 minutos em tempo quase atual. A precipitação média sobre as 13 estações meteorológicas do INMET na bacia do Paraná foi de $42 \mathrm{~mm}$, enquanto, para o CMOPRH, foi de $52 \mathrm{~mm}$ para o evento mostrado na Fig. 7. A Fig. 8 mostra a chuva acumulada do mesmo evento obtida da simulação com o modelo ARPS.

As parametrizações do modelo ARPS foram configuradas, e as estimativas de precipitação via satélite ajustadas. Os dados da modelagem numérica com o sistema ARPS e das estimativas de chuva por satélite, rede telemétrica, radar e integrada via ANOBES foram utilizados no modelo SMAP para simular vazões nas bacias da 


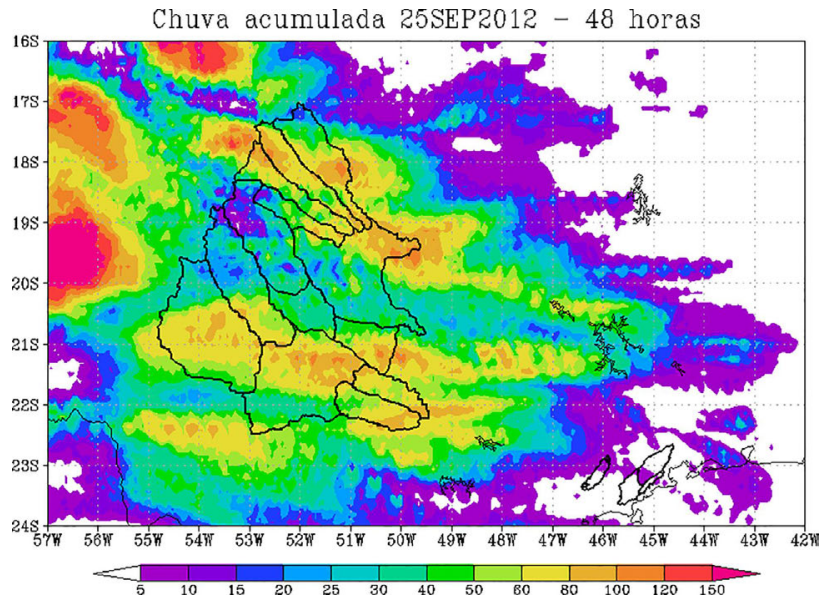

Figura 7 - Estimativa de precipitação na área bacias da CESP realizada com o CMORPH, entre 00:00 UTC de 24/09 e 00:00 UTC de 26/09/ 2012. Contorno indica limite das bacias hidrográficas (Fig. 1).

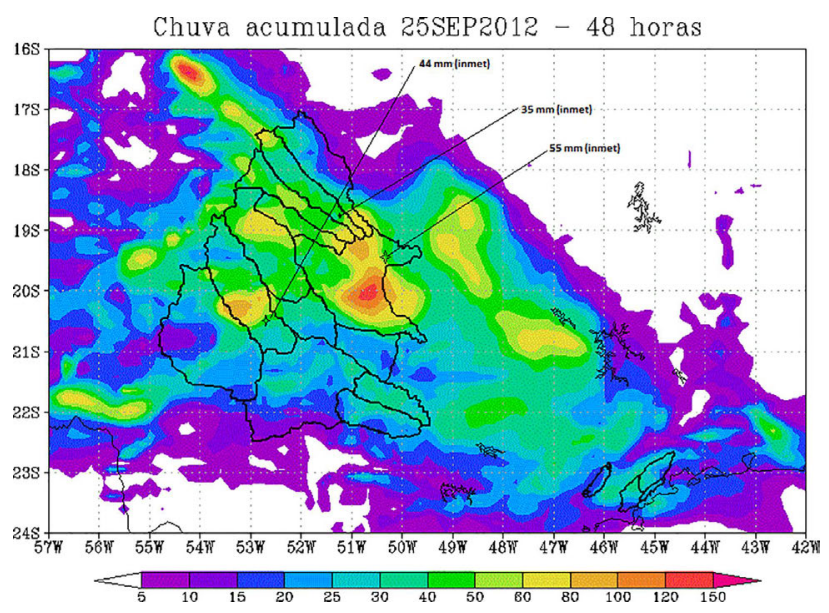

Figura 8 - Distribuição espacial de chuva acumulada simulada com o sistema ARPS sobre as bacias da CESP para de 25/09/2012. Contorno indica as bacias hidrográficas. Estão destacados três pontos de medição do INMET.

CESP. Os resultados foram comparados com as observações de vazão disponíveis.

\section{Resultados e Discussão}

Todos os módulos descritos acima foram desenvolvidos, permitindo a realização de análise de desempenho da rede telemétrica da CESP e correspondente calibração e validação do modelo hidrológico SMAP. Estudos realizados para calibração e validação do modelo hidrológico SMAP com dados da rede telemétrica da CESP indicaram baixo desempenho. No presente trabalho, desenvolveramse seis (6) técnicas de estimativa (CST, Thiessen (Brassel e Reif, 1979), ANOBES e CMORPH) e previsão (ARPS e GFS) de chuva diária para um horizonte de até quinze dias à frente. Utilizaram-se bases de dados com alta resolução espaço-temporal integradas aos dados da rede telemétrica da CESP. Após a utilização de novas estimativas de chuva acima por meio de sensoriamento remoto, integrados com a rede telemétrica, o desempenho da simulação hidrológica com o modelo SMAP foi significativamente melhor. Destacam-se, nesta secção, os principais resultados das análises com a ANOBES e modelos de previsão ARPS e hidrológica com SMAP por meio de um evento de precipitação acumulada elevada.

\subsection{ANOBES}

O evento de precipitação ocorrido no dia 20/06/2012 foi escolhido devido ao considerável volume de chuva observado e disponibilidade de dados pluviométricos. Nesse dia, a técnica CST subestimou a precipitação com relação à observação dos postos pluviométricos. O ANOBES foi executado e como resultado fornece a integração satélite-pluviômetro (análise), a diferença observada (análise-observação), e a matriz para análise da variância do erro da integração. A Fig. 9 mostra o campo resultado da integração via análise ANOBES. Verifica-se a influência da taxa de precipitação observada pelos pluviômetros sobre o campo de precipitação estimado pelo CST após a integração dos dados. De maneira geral, a matriz de precipitação obtida pelo CST, em que a taxa de precipitação foi subestimada, passa a ter valores maiores devido à influência dos pluviômetros.

Os píxeis mais próximos dos postos pluviométricos tiveram maior influência, uma vez que possui maior correlação em função da distância. Píxeis distantes também foram considerados, porém com menor peso. A Fig. 10 ilustra a matriz diferença análise - observação.

Nota-se, no campo de diferença entre análise e observação, áreas em que houve maior peso da integração

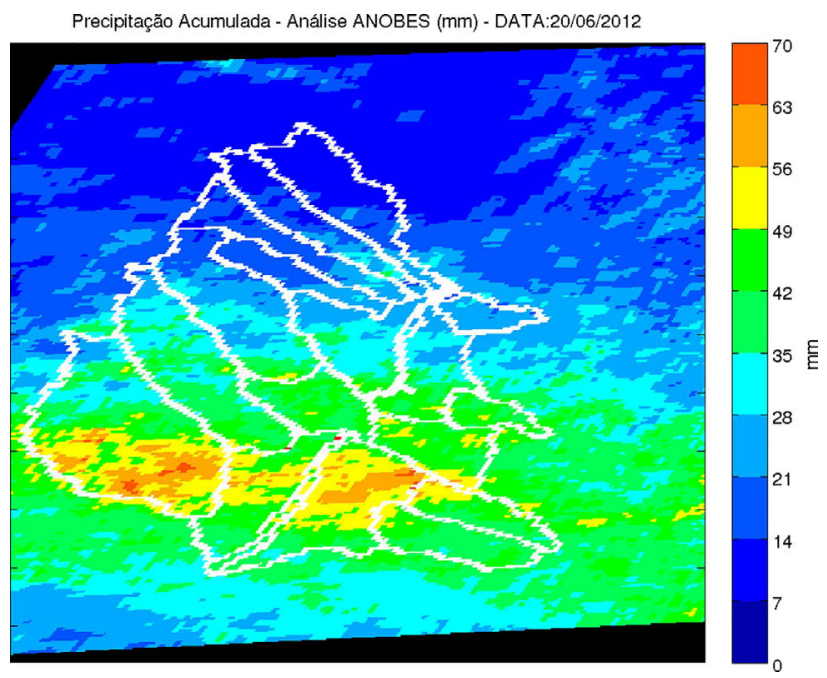

Figura 9 - Campo de precipitação acumulada mediante análise ANO$\mathrm{BES}$, resultado da integração. A escala de cores indica o total diário de chuva acumulada $(\mathrm{mm})$. 


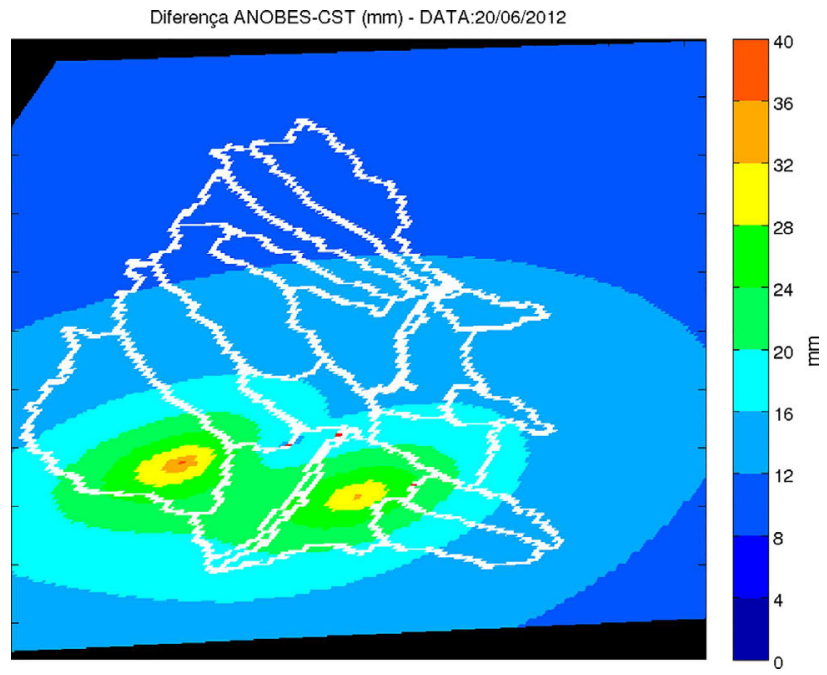

Figura 10 - Campo de precipitação diferença análise (ANOBES) menos observação (CST). A escala de cores indica a diferença de chuva em $(\mathrm{mm})$.

realizada, caracterizadas pela aproximação das isoietas com valor máximo de $38 \mathrm{~mm}$ no centro de regiões com maiores diferenças entre CST - Pluviômetros. Por outro lado, para regiões em que há concordância entre estimativa e observação, as diferenças encontradas foram de aproximadamente $9 \mathrm{~mm}$ após a integração realizada pelo ANOBES. A Fig. 11 apresenta o campo de análise da variância do erro da integração. O campo de erro esperado para a integração pode ser utilizado para se localizar a melhor disposição possível para a rede pluviométrica de modo a minimizar o erro da integração. Uma das principais vantagens desse método é a possibilidade de analisar a variância do erro esperado mesmo antes do esquema de

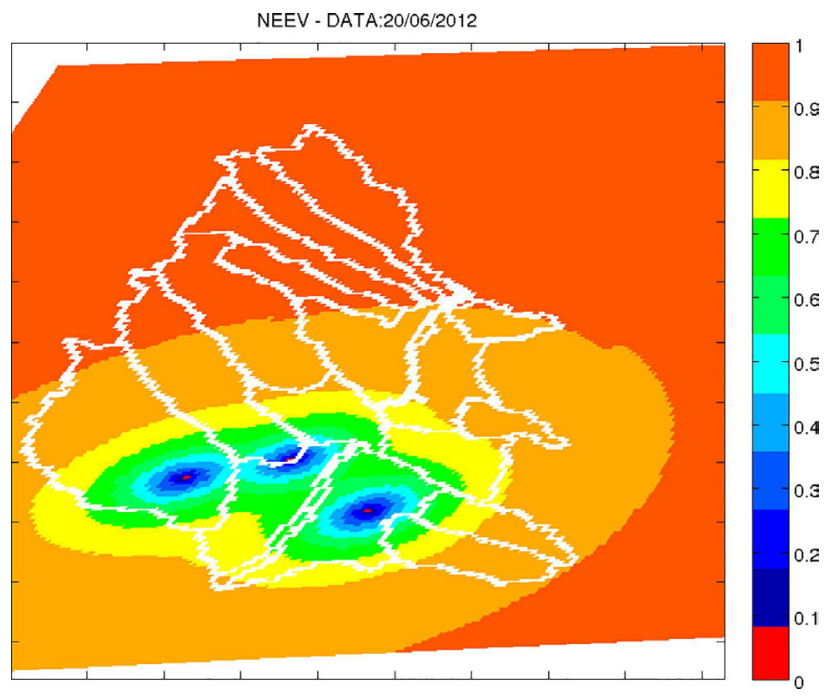

Figura 11 - Campo de erro esperado para a integração. A escala de cores indica o erro normalizado $(0-1,0)$ de integração dos dados CST - Pluviômetro. integração ANOBES ser utilizado (Negri et al., 2002). Cada pluviômetro tem um raio de influência limitado que é pré-determinado pelo comportamento estatístico do sistema precipitante. Esse conhecimento é essencial para aprimoramento da distribuição dos postos pluviométricos. Sugere-se o aumento da densidade de pluviômetros nas bacias estudadas. Em geral, os postos fluviométrico e pluviométrico estão instalados no exutório das bacias, o que diminui a representatividade espacial da medição de precipitação.

\subsection{ARPS}

Os resultados obtidos com as correlações entre ARPS e CMORPH mostram que, de forma geral o ARPS tende a superestimar a precipitação sobre as sub-bacias com relação ao CMORPH. O CMORPH apresenta as melhores estimativas para chuva convectiva e piores para chuvas estratiformes provenientes de nuvens baixas (nuvens quentes). A Fig. 12 mostra a correlação calculada entre ARPS e CMORPH para um conjunto de sub-bacias. Notam-se valores de coeficiente b positivos, o que indica superestimativa com a modelagem em relação ao CMORPH. Umas das razões que podem induzir superestimativa com o ARPS seria umidade do solo superior a real. São poucos os dados de umidade do solo disponível e confiáveis sobre o Brasil, mas há estimativas de umidade de solo por meio de satélite ambientais, não utilizadas no presente estudo. No entanto, no estado do Espirito Santo, existem 25 estações meteorológicas automáticas (EMAs) recentes com medições de umidade do solo, e notou-se que os valores iniciais provenientes do GFS, eram em torno de $65 \%$ superior aos aferidos pelas EMAs.

Desse modo, para o período de 2014, optou-se por ajustar a umidade do solo com redução em torno de $65 \%$ do valor médio para todo o Brasil. Ressalta-se que há estimativas de umidade do solo do sistema SMOS (Soil Moisture Ocean Salinity) (Kerr et al., 2010), entretanto não foram utilizadas para assimilação com o ARPS. Optou-se por utilizar o mesmo fator de correção de $65 \%$ para toda a área de domínio do modelo. Foram efetuados cálculos de correlação entre ARPS e CMORPH para todo o período de 2013 (com umidade do solo proveniente do GFS) e período de 2014 (com umidade do solo em 35\% do GFS). O comportamento observado para todos os meses do ano foi aproximadamente similar. Desse modo, destacam-se apenas os meses de fevereiro e março de 2013 e 2014. Nota-se considerável redução nas superestimativas com ARPS apenas com a redução de umidade do solo. Em geral, para os meses de verão, houve aumento nos índices de correlação. Para os meses de outono, houve leve diminuição para a correlação, mas diminuem consideravelmente as superestimativas. Ressalta-se que se compararam anos diferentes. Os eventos de 2013 foram simulados novamente com ajuste da umidade do solo. 

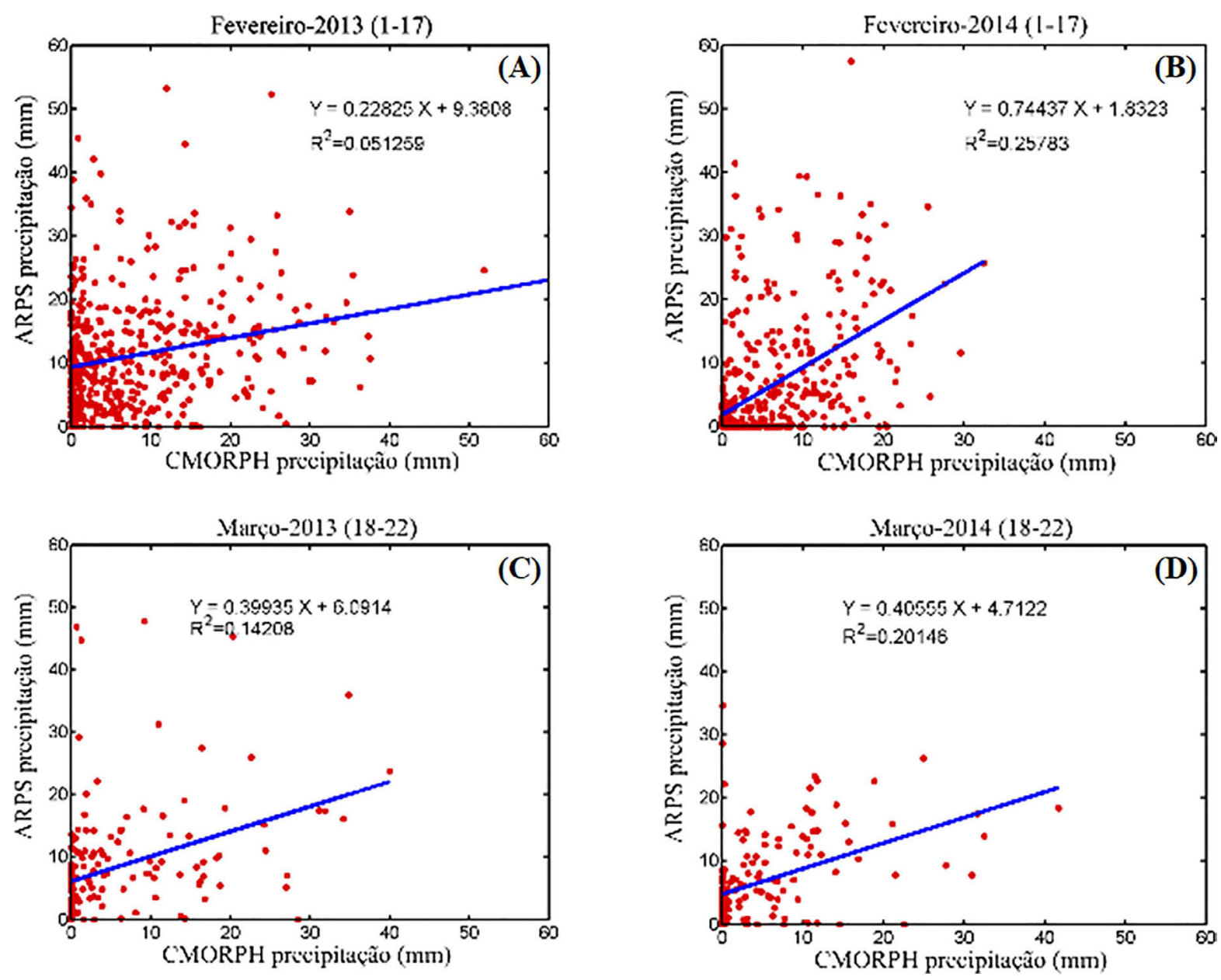

Figura 12 - Dispersão de chuva acumulada entre ARPS e CMORPH para o conjunto de sub-bacias indicada na Fig. 1. Equação de regressão linear, coeficiente de variação, mês, ano e conjunto estão indicados.

O procedimento pode ser aplicado para cada estação do ano para com vistas à obtenção de resultados mais satisfatórios. Além disso, ressalta-se que a melhor estimativa de chuva foi obtida com a ANOBES e, portanto, os resultados da modelagem com o sistema ARPS foram comparados com a ANOBES. Os resultados apresentados embora parciais servem de base para análises futuras. De modo geral, o ajuste da umidade do solo reduziu o viés positivo do modelo ARPS.

Na Fig. 13, são mostrados alguns gráficos de CSI (índice de sucesso crítico) e POD (probabilidade de detecção) para duas sub-bacias na região do Paraná e na região do Paraíba do Sul, as mais representativas do comportamento médio desses índices na região. De modo geral, na região da bacia do Paraná, os índices CSI e POD são levemente superiores aos encontrados na região das bacias do Paraíba do Sul. Ressalta-se que esse pior desempenho pode ser devido ao limitado desempenho do CMORPH para situações de chuva proveniente de nuvens baixas. Com as estimativas ANOBES, será possível obter esses índices para o ARPS de maneira mais acurada.

\subsection{Simulações com SMAP}

O modelo de previsão de chuva-vazão SMAP utiliza dados históricos de precipitação recente, dados de previsão de precipitação e as características da bacia. As estimativas de precipitação CMORPH e ANOBES (CST + telemetria) e previsão de precipitação com ARPS foram utilizadas na simulação de vazão com o modelo SMAP. A calibração do modelo SMAP é realizada com evento precipitação mais recente passado para que a vazão estimada mais próxima futura seja mais aderente em relação à vazão observada. A simulação hidrológica com o SMAP para diferentes séries de estimativas de precipitação (e.g., CMORPH, ARPS e CST) utiliza parâmetros específicos de cada bacia, pois representam as características físicas intrínsecas de cada bacia. Dessa forma, os parâmetros de calibração de uma bacia são os mesmos para os diferentes dados de precipitação. A calibração foi realizada para todas as bacias da CESP com dados de precipitação médias diárias. O modelo de simulação hidrológica SMAP foi aplicado para comparar os níveis de ajuste entre as va- 


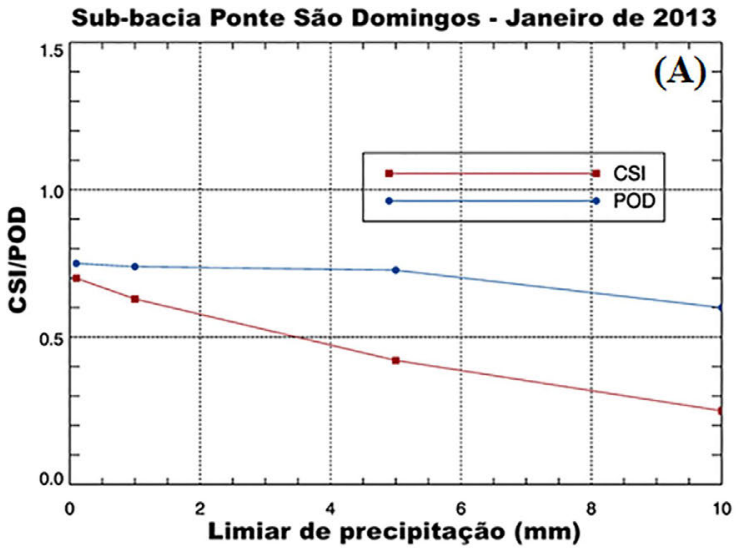

Sub-bacia Ponte São Domingos - Setembro de 2013

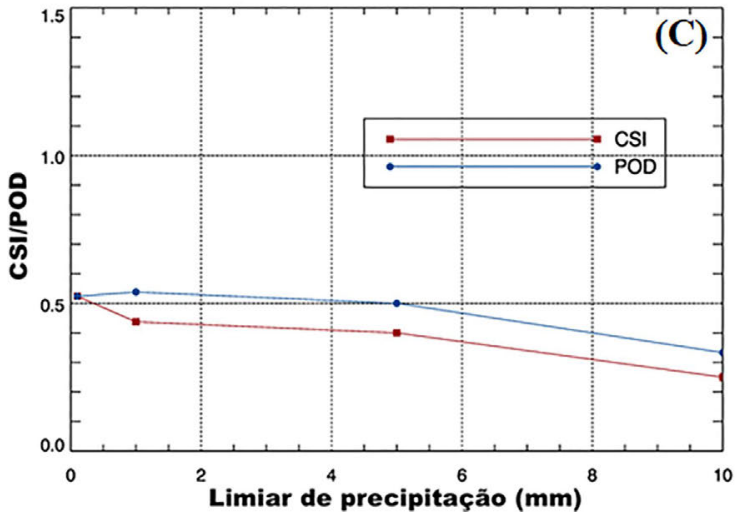

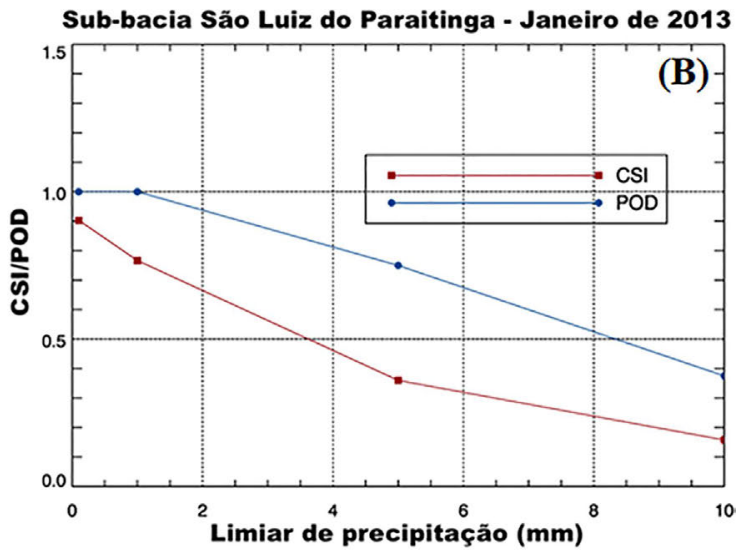

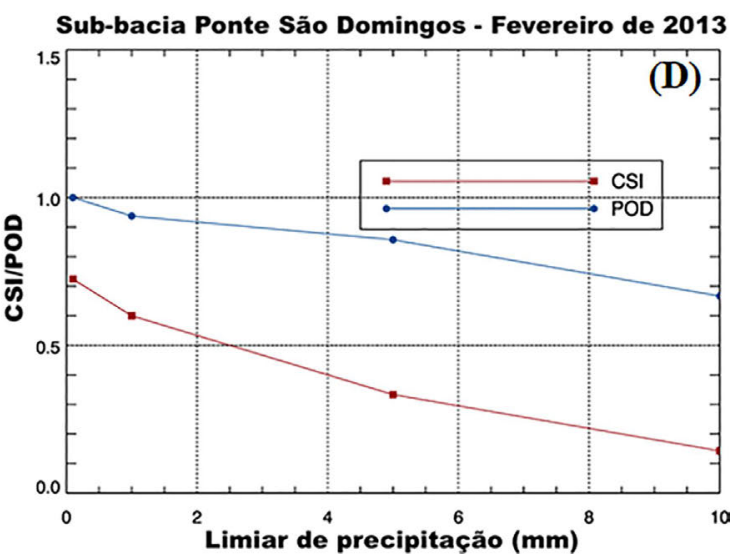

Figura 13 - Análise de desempenho do modelo ARPS contra a estimativa de precipitação CMORPH para o índice de sucesso crítico (CSI) e probabilidade de deteç̧ão (POD) nas sub-bacias Ponte São Domingos na região do Paraná e São Luiz do Paraitinga no Paraíba do Sul mostradas na Fig. 1 (11 e 20 , respectivamente). Mês e ano indicados.

zões médias diárias verificadas nas sub-bacias e as informações fluviométricas e as vazões médias diárias calculadas pelo modelo com a utilização das precipitações médias diárias estimadas nas sub-bacias pelos processos de Thiessen, CST, ANOBES, CMORPH e ARPS. Os parâmetros do modelo SMAP ajustados para cada bacia (não mostrado) foram: a capacidade de saturação do solo (mm); constante de recessão do escoamento superficial (dias); parâmetro de recarga subterrânea (\%); abstração inicial (mm); capacidade de campo (\%); e constante de recessão do escoamento básico (dias). Assim, foram definidos os conjuntos ótimos de parâmetros para emprego nas simulações de vazão com o modelo SMAP.

Desta forma, como previamente explicado, simulações com o modelo SMAP foram realizadas com base nas várias estimativas de precipitação média diária nas bacias da CESP, com destaque, neste manuscrito, para as realizadas com o CMORPH, técnica CST e ARPS. As simulações hidrológicas com a precipitação média estimada para cada sub-bacia foram classificadas conforme o melhor ajuste entre as vazões médias diárias calculadas pelo modelo SMAP e as vazões médias diárias observadas nos postos fluviométricos. Os hidrogramas simulados e obser- vados foram comparados por meio de testes estatísticos para as vazões médias e picos de vazão. A Fig. 14 mostra os resultados para a bacia do rio Peixe em Florida Peixoto (Fig. 1). Nota-se o melhor desempenho para a estimativa CMORPH e para as simulações com o ARPS ao longo do ano de 2012 com erro relativo entre vazão média simulada e observada de $1 \%$ em ambas as simulações. A técnica CST tende a subestimar as vazões com erro relativo de $21 \%$.

Resultados similares foram obtidos para outras subbacias a exemplo das simulações para a bacia do rio do Paraitinga (Fig. 15) com erro relativo de 5\% em ambas as simulações com as estimativas de precipitação média diária CMORPH e ARPS.

A Tabela 2 mostra o desempenho geral das simulações de vazão média diária em relação as vazões médias diárias medidas em cada sub-bacia para o período de 20 de fevereiro a 31 de dezembro de 2013 com dados de precipitação média diária obtidas das técnicas Thiessen, CST, CMORPH e ARPS. Os resultados sugerem um melhor desempenho das simulações realizadas com a estimativa de precipitação do CMORPH, seguida das com o ARPS, Thiessen e CST. Ressalta-se que a estimativa de chuva 
Bacia do rio do Peixe em Flórida Paulista

Aplicação Modelo SMAP com precipitação média estimada por CMORPH - Período: 01/12/2011 a 30/11/2012

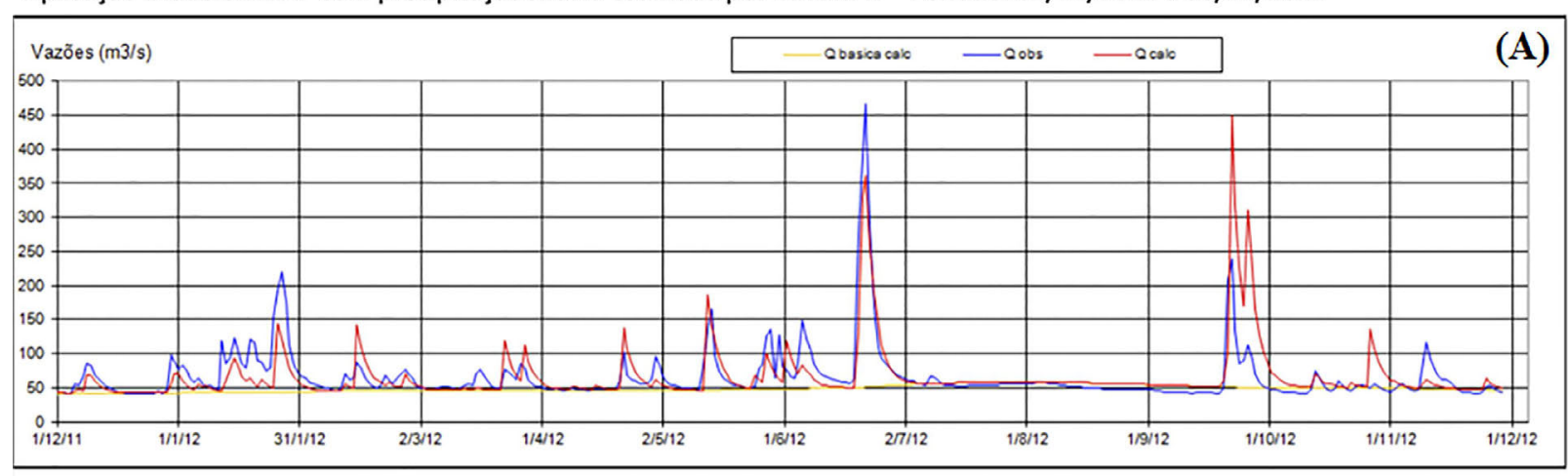

Vazão observada média $=65,9 \mathrm{~m}^{3} / \mathrm{s}$

Vazão calculada média $=66,5 \mathrm{~m}^{3} / \mathrm{s}$

Erro Relativo $=1 \%$

Erro Quadrático Relativo $=36,0$

Bacia do rio do Peixe em Flórida Paulista

Aplicação Modelo SMAP com precipitação média estimada por CST - Período: 01/12/2011 a 30/11/2012

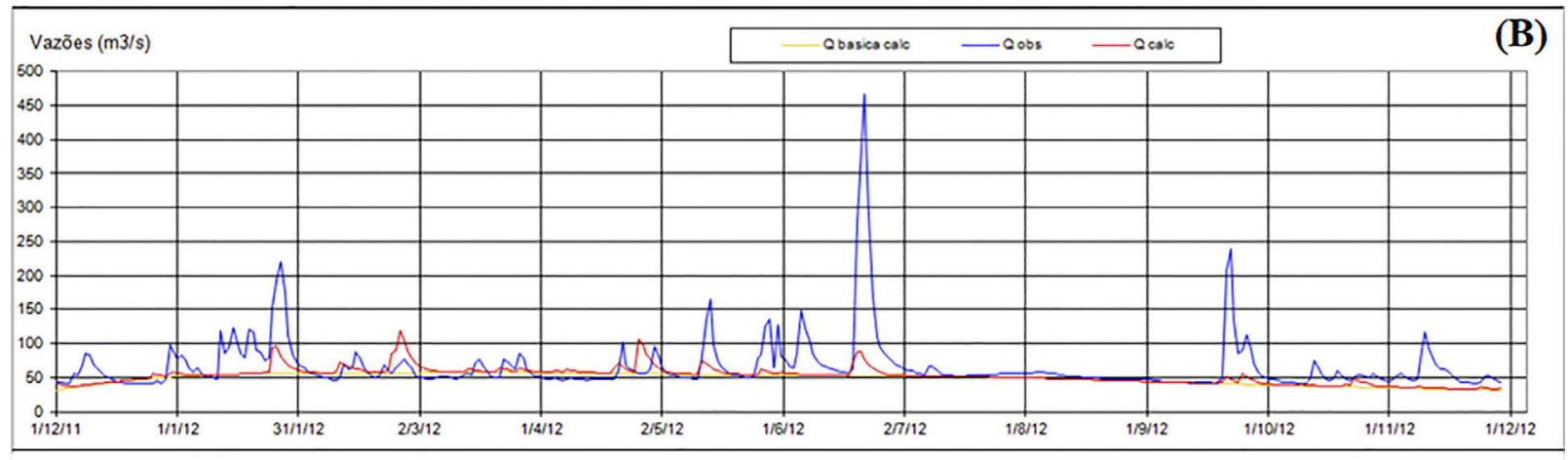

Vazão observada média $=65,9 \mathrm{~m}^{3} / \mathrm{s}$

Vazão calculada média $=52,2 \mathrm{~m}^{3} / \mathrm{s}$

Erro Relativo $=-21 \%$

Erro Quadrático Relativo $=27,8$

Bacia do rio do Peixe em Flórida Paulista

Aplicação Modelo SMAP com precipitação média estimada por CMORPH - Período: 01/12/2011 a 30/11/2012

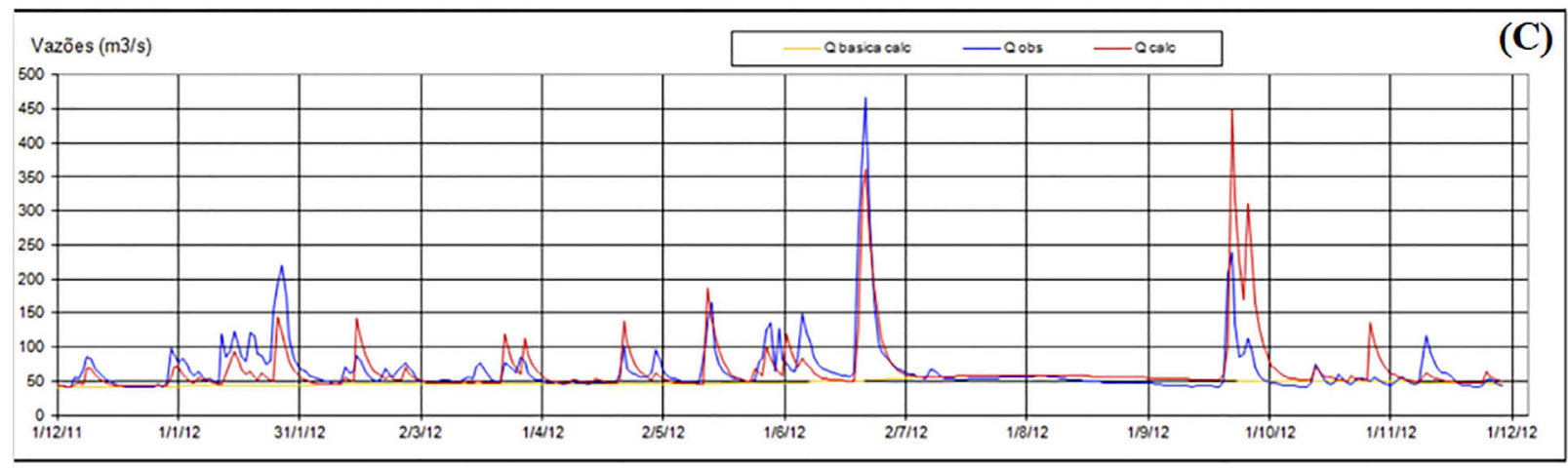

Vazão observada média $=65,9 \mathrm{~m}^{3} / \mathrm{s}$

Vazão calculada média $=66,5 \mathrm{~m}^{3} / \mathrm{s}$

Erro Relativo $=1 \%$

Erro Quadrático Relativo $=36,0$

Figura 14 - Simulações de vazões para a bacia do rio do Peixe entre 01/12/2011 e 30/11/2012 com CMORPH (topo), CST (meio) e ARPS (baixo). Hidrogramas observado (azul) e simulado (vermelho) e escoamento básico (amarelo) estão indicados. Também estão indicadas as vazões médias observadas e simuladas com respectivos erros relativo e quadrático. 
Bacia do rio Paraitinga em São Luiz do Paraitinga

Aplicação Modelo SMAP com precipitação média estimada por CMORPH - Período: 01/12/2011 a 30/11/2012

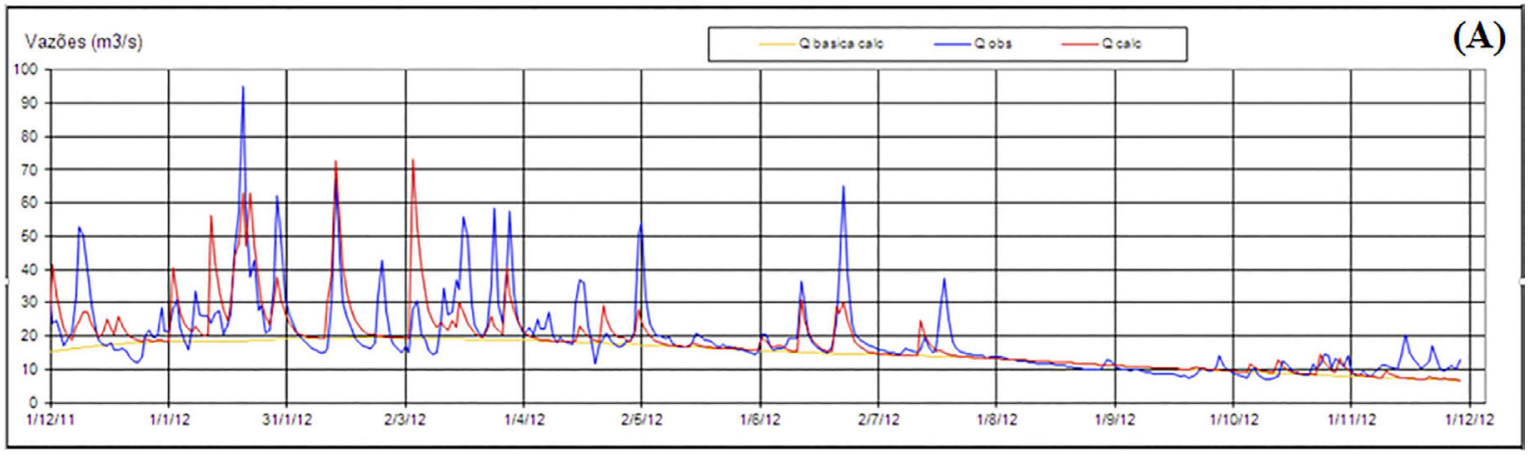

Vazão observada média $=19,3 \mathrm{~m}^{3} / \mathrm{s}$

Vazão calculada média $=18,4 \mathrm{~m}^{3} / \mathrm{s}$

Erro Relativo $=-5 \%$

Erro Quadrático Relativo $=29,0$

Bacia do rio Paraitinga em São Luiz do Paraitinga

Aplicação Modelo SMAP com precipitação média estimada por ARPS - Período: 01/12/2011 a 30/11/2012

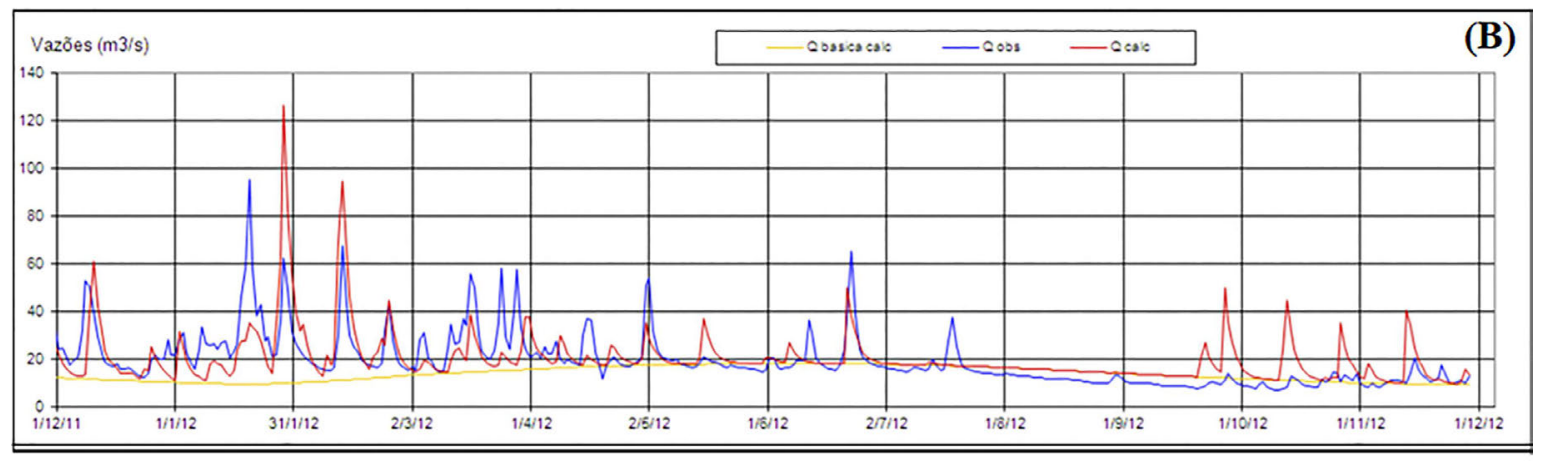

Vazão observada média $=19,3 \mathrm{~m}^{3} / \mathrm{s}$

Vazão calculada média $=20,3 \mathrm{~m}^{3} / \mathrm{s}$

Erro Relativo $=5 \%$

Erro Quadrático Relativo $=118,9$

Figura 15 - Simulações de vazões para a bacia do rio do Paraitinga entre 01/12/2011 e 30/11/2012 com CMORPH (topo) e ARPS (baixo). Hidrogramas observado (azul) e simulado (vermelho) e escoamento básico (amarelo) estão indicados. Também estão indicadas as vazões médias observadas e simuladas com respectivos erros relativo e quadrático.

CST é obtida diretamente das imagens do canal infravermelho do satélite em tempo quase real enquanto as respectivas estimativas com o CMORPH ficam disponíveis $a$ posteriori da ordem de dias. Assim, a técnica de estimativa de precipitação para previsão hidrológica é a CST integrada com as medições da rede telemétrica cujos resultados são mostrados a seguir.

A estimativa de precipitação pela técnica CST melhorou com a integração desta com as medições de precipitação da rede telemétrica da CESP por meio da ANOBES, conforme mostrado na Tabela 3. O máximo coeficiente de correlação entre CST e pluviômetros foi obtido para a sub-bacia Ilha Solteiro Norte $(\mathrm{R}=0,79)$, e o mínimo para a sub-bacia de Ilha Solteira Sul $(\mathrm{R}=0,24)$, conforme mostrado na Tabela 3.

A comparação entre ANOBES (integração entre CST e rede telemétrica) e pluviômetros indica máxima correlação na sub-bacia de Ilha Solteira Oeste $(R=0,96)$, enquanto o valor mínimo foi obtido para a sub-bacia de Ilha Solteira Sul $(\mathrm{R}=0,63)$, conforme mostrado na Tabela 3 .

\section{Conclusões}

O presente trabalho de pesquisa e desenvolvimento utilizou novas metodologias de estimativa e previsão de chuva, e outras de caráter mais geral no que se refere à integração de dados e modelagem numérica aplicada à previsão hidrológica com os sistemas ANOBES e ARPS. As principais características e inovações foram: 1) uso de modelagem ARPS de alta resolução $(12-\mathrm{km})$ com até 5 dias de antecedência para aplicações em hidrologia da CESP com ajuste de umidade do solo a partir de medições em parte do domínio de previsão; 2) uso da modelagem 
Tabela 2 - Desempenho das simulações da vazão média diária do modelo SMAP com precipitação média diária estimada com as técnicas Thiessen, CST, CMOPRH e ARPS para o período de 20 de fevereiro a 31 de dezembro de 2013. Estão indicados o coeficiente de variação $\left(R^{2}\right)$, erro relativo (ER), erro quadrático relativo (EQR) e a qualidade do ajuste (ótimo, bom, médio e baixo) entre vazão média diária simulada e vazão média diária medida em cada sub-bacia. Sub-bacias do rio Paraná: FLT Florida Paulista; SCB - Salto Carlos Botelho; FBU - Fazenda Buriti; POV - Porto Velho; FSS - Fazenda São Sebastião; FBA - Fazenda Bálsamo; FAM - Fazenda Mumbela (Mumbela Inferior); FAL - Fazenda Lajofreu (Mumbela Superior); FRO - Fazenda Rondinha (Jataí). Sub-bacias do Rio Paraíba do Sul: FAP - Fazenda Palmeiras; SLP - São Luiz do Paraitinga; FAS - Fazenda Santana; CAJ - Cachoeira do Jaguaribe. Detalhes das sub-bacias na Fig. 1.

\begin{tabular}{|c|c|c|c|c|c|c|c|c|}
\hline \multirow[b]{2}{*}{ Sub-bacia } & \multicolumn{4}{|c|}{ Thiessen } & \multicolumn{4}{|c|}{ CST } \\
\hline & $\mathrm{R}^{2}$ & $\mathrm{ER}(\%)$ & EQR & Ajuste & $\mathrm{R}^{2}$ & $\mathrm{ER}(\%)$ & EQR & Ajuste \\
\hline FLT & 0,30 & -3 & 101 & médio & 0,10 & -18 & 41 & baixo \\
\hline SCB & 0,31 & -5 & 119 & médio & 0,25 & -19 & 46 & baixo \\
\hline FBU & 0,08 & -14 & 24 & baixo & 0,21 & -5 & 11 & baixo \\
\hline POV & 0,19 & -15 & 25 & baixo & 0,23 & -15 & 17 & baixo \\
\hline FSS & 0,42 & -11 & 21 & médio & 0,47 & -12 & 13 & baixo \\
\hline FBA & 0,37 & -7 & 28 & médio & 0,41 & -8 & 15 & médio \\
\hline FAM & 0,29 & -3 & 45 & médio & 0,21 & 4 & 55 & médio \\
\hline FAL & 0,48 & -13 & 31 & médio & 0,15 & 0 & 141 & médio \\
\hline FRO & 0,48 & -25 & 45 & médio & 0,23 & 0 & 210 & médio \\
\hline FAP & 0,21 & -30 & 40 & médio & 0,04 & 217 & 12767 & baixo \\
\hline SLP & 0,28 & -5 & 68 & médio & 0,12 & 224 & 7065 & baixo \\
\hline FAZ & 0,46 & -4 & 69 & médio & 0,15 & 263 & 13954 & baixo \\
\hline CAJ & 0,26 & 0 & 129 & médio & 0,04 & 529 & 78179 & baixo \\
\hline
\end{tabular}

com GFS num horizonte de até 15 dias à frente; 3) estimativa de chuva com dados de alta resolução espaço (8-km) temporal (15 minutos) com a técnica CST integrada à telemetria da CESP via ANOBES; 4) estimativa de chuva diária com o CMORPH com resolução de 8-km para as bacias da CESP; 5) dados de previsão (ARPS e GFS) e estimativa de chuva diária média (Thiessen, CST, CMORPH, radar e ANOBES (integração CST e telemetria) para dezessete sub-bacias da CESP; 6) análise de desempenho do SMAP com as fontes de dados de precipitação acima no período de 2011 a 2015 com obtenção de desempenho contra a vazão observada, aqui evidenciados por meio de resultados globais e para períodos e subbacias específicos.

Após a utilização de novas estimativas de chuva por meio de sensoriamento remoto, integrados com a rede telemétrica, o desempenho da simulação hidrológica com o modelo SMAP melhorou significativamente, particularmente com a estimativa de precipitação média diária da técnica CMORPH, conforme indicam os resultados apresentados neste manuscrito. Notadamente, o uso das previsões e estimativas de precipitação com o modelo ARPS, ANOBES, respectivamente, e a estimativa com CMORPH resultaram em excelente desempenho para as sub-bacias da CESP comparadas com o sistema de previsão funda-
Tabela 3 - Coeficientes de correlação (R) e de determinação $\left(R^{2}\right)$ entre precipitação média mensal obtida da técnica CST (A) e da integração ANOBES (CST e rede telemétrica) (B) e pluviômetros da CESP para dezessete sub-bacias do rio Paraná e do rio Paraíba do Sul entre novembro de 2011 e novembro de 2012. Nomes das sub-bacias indicados por três letras (Fig. 1).

\begin{tabular}{|c|c|c|c|c|c|}
\hline \multicolumn{6}{|l|}{ A } \\
\hline Sub-bacia & $\mathrm{R}^{2}$ & $\mathrm{R}$ & Sub-bacia & $\mathrm{R} 2$ & $\mathrm{R}$ \\
\hline FRO & 0,55 & 0,74 & VOI & 0,46 & 0,67 \\
\hline FAL & 0,48 & 0,69 & FPA & 0,05 & 0,24 \\
\hline FAM & 0,44 & 0,69 & TRI & 0,16 & 0,40 \\
\hline FBA & 0,40 & 0,63 & JUP & 0,30 & 0,55 \\
\hline FSS & 0,34 & 0,58 & VLP & 0,21 & 0,46 \\
\hline POV & 0,35 & 0,59 & VOP & 0,42 & 0,65 \\
\hline FBU & 0,42 & 0,66 & $\mathrm{SCB}$ & 0,12 & 0,34 \\
\hline VLI & 0,52 & 0,72 & FLT & 0,14 & 0,38 \\
\hline PSD & 0,63 & 0,79 & & & \\
\hline \multicolumn{6}{|l|}{ B } \\
\hline Sub-bacia & $\mathrm{R}^{2}$ & $\mathrm{R}$ & Sub-bacia & $\mathrm{R}^{2}$ & $\mathrm{R}$ \\
\hline FRO & 0,73 & 0,85 & VOI & 0,92 & 0,96 \\
\hline FAL & 0,75 & 0,86 & FPA & 0,39 & 0,63 \\
\hline FAM & 0,77 & 0,87 & TRI & 0,74 & 0,86 \\
\hline FBA & 0,77 & 0,88 & JUP & 0,91 & 0,95 \\
\hline FSS & 0,73 & 0,85 & VLP & 0,88 & 0,94 \\
\hline POV & 0,75 & 0,87 & VOP & 0,89 & 0,94 \\
\hline FBU & 0,70 & 0,83 & $\mathrm{SCB}$ & 0,78 & 0,88 \\
\hline VLI & 0,90 & 0,95 & FLT & 0,79 & 0.89 \\
\hline PSD & 0,87 & 0,93 & & & \\
\hline
\end{tabular}

mentado apenas na rede telemétrica e previsões de precipitação com modelos de menor resolução espaço-temporal (e.g., o modelo ETA empregado pelo INPE).

O trabalho de pesquisa incluiu a identificação da previsão e estimativa de chuva de melhor desempenho a partir das análises de chuva e da previsão hidrológica verificada com dados de vazão observada. Além das pesquisas acima, realizaram-se análises de precipitação com radar de São Paulo para as bacias dos rios Paraibuna e Jaguari, tendo em vistas as estratégias na crise hídrica de 2014/ 2015, particularmente nessas duas bacias hidrográficas, cujos resultados serão apresentados em outra publicação. Os estudos indicaram o ARPS e o ANOBES, que integra a rede telemétrica e técnica CST, como os de melhor desempenho em geral. Para o caso das bacias do leste de São Paulo (Paraíba do Sul), a estimativa de chuva com o radar meteorológico do DAEE foi o método que apresentou melhor resultados em razão das características do relevo daquela região.

O sistema de análise objetiva estatística ANOBES aperfeiçoou a estimativa de chuva média diária, pois considerou as fontes de erro diversas e também as características espaciais da chuva na integração de dados. Portanto, 
todas as demais estimativas, por meio da técnica CST, método de Thiessen, e CMORPH, podem também ser utilizados de modo a se ter e avaliar incertezas e variabilidades pelo usuário da CESP. A operação de sistema em tempo real (Fig. 2) requer um sistema de processamento de dados de alto desempenho para o modelo ARPS e vários de estimativa de chuva, dado que o atual existente, decorridos três anos, está obsoleto. Complementarmente, o uso operacional de dados de satélite requer a aquisição de licenças de uso operacional. Há, também, a necessidade de recursos humanos especializados para a manutenção diária do sistema de informação e previsão, um dos aspectos mais requer atenção no âmbito do Brasil.

Sugere-se, ao final, como futuros trabalhos: 1) assimilação de dados 4D nos ARPS; 2) projeto de ampliação da rede telemétrica; 3) uso de modelos hidrológicos distribuídos (e.g., TOPMODEL e RNA); 4) previsão por conjuntos com ARPS; 5) sistema de controle e qualidade de dados; 6) implementação de outras técnicas de estimativa de satélite (e.g., PERSIAN); e 7) previsão hidrológica probabilística.

\section{Agradecimentos}

Os autores gostariam de expressar à CESP seus agradecimentos pelo fornecimento dos bancos de dados da rede telemétrica, e demais informações de suas bacias para realização desta pesquisa. Os autores gostariam de agradecer ao revisor anônimo pela meticulosa avaliação que enriqueceu as análises e o polimento do manuscrito. Este projeto de pesquisa e desenvolvimento foi financiado pela CESP sob número ANEEL PD-0061-0035/2013. O primeiro autor agradece ao $\mathrm{CNPq}$ pelo suporte por meio do processo n ${ }^{\mathrm{o}} 301149 / 2017-8$.

\section{Referências}

ADLER, R.F.; NEGRI, A.J. A satellite infrared technique to estimate tropical convective and stratiform rainfall. Journal of Applied Meteorology, v. 27, n. 1, p. 30-51, 1988.

ANDRADE, N.L.R; XAVIER, F.V.; ALVES, R.F.; SILVEIRA, A. OLIVEIRA, C.U.R. Caracterização morfométrica e pluviométrica da Bacia do Rio Manso - MT. Revista Geociências, v. 27, n. 2, p. 237-248, 2008.

ASSELIN, R. Frequency filter for time integrations. Monthly Weather Review, v. 100, n. 6, p. 487-490, 1972.

ATKINSON, B.W. Meso-scale Atmospheric Circulation. London: Academic Press, 495 p, 1981.

BLUESTEIN, H.B. Synoptic-Dynamic Meteorology in Midlatitudes. Volume II: Observations and Theory of Weather Systems. New York: Oxford University Press, $594 \mathrm{p}, 1993$.

BRASSEL, K.E.; REIF, D.A. A procedure to generate Thiessen Polygons. Geographical Analysis. v. 11, n. 3, p. 289-303, 1979.
CALVETTI, L.; BENETI, C.A.A.; PEREIRA FILHO, A.J., Integração do radar meteorológico Doppler do SIMEPAR e uma rede de pluviòmetros para a estimativa da precipitação. Anais XI Simpósio Brasileiro de Sensoriamento Remoto, Belo Horizonte, p. 1137-1144, 2003.

CHEN, F.; MITCHELL, K.; SCHAAKE, J.; XUE, Y.; PAN, H.L.; KOREN, V.; DUAN, Q.Y.; EK, M.; BETTS, A. Modeling of land surface evaporation by four schemes and comparison with FIFE observations. Journal of Geophysical Research Atmospheres, v. 101, n. D3, p. 7251-7268, 1996.

CHOU, M.D.; SUAREZ, M.J.; HO, C.H.; YAN, M.M.H.; LEE, K.T. Parameterizations for cloud overlapping and shortwave single scattering properties for use in general circulation and cloud ensemble models. Journal Climate, v. 11, n. 2, p. 202-214, 1998.

CHOU, M.D.; LEE, K.T. Parameterizations for the absorption of solar radiation by water vapor and ozone. Journal of the Atmospheric Sciences, v. 53, n. 8, p. 1204-1208, 1996.

CHUNYAN, L.; KRAJEWSKI, F.W. A comparison of calculations of radar-rainfall hourly accumulations. Water Resources Bulletin, v. 32, n. 2, p. 305-315, 1996.

CLOUGH, S.A.; IACONO, M. J.; MONCET, J.L. Line-by-line calculations of atmospheric fluxes and cooling rates: Application to water vapor. Journal Geophysical Research, v. 97, n. D14, p. 15761-15785, 1992.

CRAWFORD, K.C. Considerations for the design of a hydrologic data network using multivariate sensors. Water Resources Research, v. 15, n. 6, p. 1752-1762, 1979.

CREUTIN, J.D.; OBLED, C. Objective analysis and mapping techniques for rainfall fields: An objective comparison. Water Resources Research., v. 18, n. 2, p. 413-431, 1982.

DONALDSON JUNIOR., R.J.; DYER, R.M.; KRAUS, M.J. An objective evaluator of techniques for predicting severe weather events. Preprints, Ninth Conf. on Severe Local Storms, Norman: American Meteorology Society, n. 197525, p. 321-326, 1975.

YANG, F.; PAN, H.; KRUEGER, S.; MOORTHI, S.; LORD, S. Evaluation of the NCEP Global Forecast System at the ARM SGP Site. Monthly Weather Review. v. 134, n. 12, p. 3668-3690, 2006.

FERRARO, R.R. SSM/I derived global rainfall estimates for climatological applications. Journal Geophysics Research, v. 102, n. D14, p. 16715-16735, 1997.

GILMORE, M.S.; STRAKA, J. M.; RASMUSSEN, E.N. Precipitation and evolution sensitivity in simulated deep convective storms: Comparisons between liquid-only and simple ice and liquid phase microphysics. Monthly Weather Review, v. 132, n. 8, p. 1897-1916, 2004.

GILMORE, M.S.; STRAKA, J. M.; RASMUSSEN, E.N. Quantitative precipitation in simulated deep convection: Sensitivity to the hail/graupel category. Preprints 15th Conf. on Numerical Weather Prediction, San Antonio: American Meteorology Society, p. 139-142, 2002.

GRELL, G.A. Prognostic evaluation of assumprions used by cumulus parameterizations. Monthly Weather Review, v. 121, n. 3, p. 764-787, 1993.

HALLAK, R. Numerical Simulation of Thundertorms in MASP. Ph.D. Thesis, IAG-USP, São Paulo, 2007. 
HAN, J.; PAN, H.L. Revision of convection and vertical diffusion schemes in the NCEP Global Forecast System. Weather and Forecasting, v. 26, n. 4, p. 520-533, 2011.

HOFSTRA, N.; NEW, M.; MCSWEENEY, C. The influence of interpolation and station netword density on the distributions and trends of climate variables in gridded daily data. Climate Dynamics, v. 35, n. 5, p 841-858, 2010.

JEWETT, B.F.; WILHELMSON, R.B.; STRAKA, J.M.; WICKER, L.J. Impact of ice parameterization on the lowlevel structure of mod- eled supercell thunderstorms. Preprints 16th Conf. on Severe Local Storms. Kananaskis Park: American Meteorology Society, p. 275-280, 1990.

JOYCE, R.J.; JANOWIAK, J.E.; ARKIN P.A.; XIE, P. CMORPH: A method that produces global precipitation estimates from passive microwave and infrared data at high spatial and temporal resolution. Journal Hydrometeorology, v. 5, n. 3, p. 487-503, 2004.

JUANG, H.-M.H. A Discretization of Deep-Atmospheric Nonhydrostatic Dynamics on Generalized Hybrid Vertical Coordinates for NCEP Global Spectral Model. NCEP Office Note 477. College Park: NCEP, 40 p, 2014.

JUANG, H.-M.H. A multiconserving discretization with enthalpy as a thermodynamic prognostic variable in generalized hybrid vertical coordinates for the NCEP global forecast system. Monthly Weather Review, v. 139, n. 5, p. 1583-1607, 2011.

JUANG, H.-M.H. A reduced spectral transform for the NCEP seasonal Forecast Global Spectral Atmospheric Model. Monthly Weather Review, v. 132, n. 4, p. 1019-1035, 2004.

JUANG, H.-M.H. Discrete Generalized Hybrid Vertical Coordinates by a Mass, Energy, and Angular Momentum Conserving Finite-Difference Scheme. NCEP Office Note 455. College Park: NCEP, 35 p, 2005.

KERR. Y.H.; WALDTEUFEL, P.; WIGNERON, J.P.; DELWART, S.; CABOT, F.; BOUTIN, J.; ESCORIHUELA, M.J.; FONT, J.; REUL, N.; GRUHIER, C.; JUGLEA, S.E.; DRINKWATER, M.R.; HAHNE, A.; MARTIN-NEIRA, M.; ECKLENBURG, S. The SMOS Mission: New tool for monitoring key elements of the global water cycle. Proceedings of the IEEE, v. 98, n. 5, p. 666-687, 2010.

KESSLER III, E. On the distribution and continuity of water substance in atmospheric circulation. Meteorology monography. American Meteorology Society, v. 10, n. 32, p. 84, 1969.

LIN, Y.L.; FARLEY R.D.; ORVILLE, H.D. Bulk parameterization of the snow field in a cloud model. Journal of Applied Meteorology, v. 22, n. 6, p. 1065-1092, 1983.

LOPES, J.E.G.; BRAGA, B.P.F.; CONEJO, J.G.L. SMAP a Simplified Hydrological Model. Applied Modelling in Catchment Hydrology, p. 167-176, 1982.

PORTO, R.L.L.; LOPES, J.E.G. Técnicas de pesquisa global de parâmetros para calibração de modelos chuva-vazão. In: IX Simpósio Brasileiro de Recursos Hídrico, Rio de Janeiro, 1991.

MARSHALL, J.S.; PALMER, W.M.K. The distribution of raindrops with size. Journal of Meteorology, v. 5, n. 4, p. 165166, 1948.

MATTHEWS, E. Atlas of Archived Vegetation, Land Use, and Seasonal Albedo Data Sets. NASA Technical Memo- randum 86199, New York: Goddard Institute for Space Studies, 1985.

MORADKHANI, H.; MESKELE, T.T. Probabilistic assessment of the satellite rainfall retrieval error translation to hydrologic response. In: GEBREMICHAEL, M; HOSSAIN, F. (eds.) Satellite Rainfall Applications for Surface Hydrology. Berlin: Springer, p. 229-244, 2010.

NEGRI, A.J.; XU, L.; ADLER, R.F. A TRMM-Calibrated infrared rainfall algorithm applied over Brazil. Journal of Geophysical Research, v. 107, n. D20, p. 8048, 2002.

PEREIRA FILHO, A.J.; VEMADO, F.; VEMADO, G.; VIEIRA REIS, F.A.G.; GIORDANO, L.C.; CERRI, R.I.; DOS SANTOS, C.C.; LOPES, E.S.S.; GRAMANI, M.F.; OGURA, A.T.; ZAINE, J.E.; DA SILVA CERRI, L.E.; FILHO, O.A.; D'AFFONSECA, F.M.; DOS SANTOS AMARAL, C. A step towards integrating CMORPH precipitation estimation with rain gauge measurements. Advances in Meteorology, v. 2018, n. 1, p. 1-24, 2018.

PEREIRA FILHO, A.J. Integração dos Dados de Precipitação do Radar Meteorológico e da Rede Telemétrica de São Paulo Via Análise Objetiva Estatística. Relatório Técnico. São Paulo: FCTH, 1999.

PEREIRA FILHO, A.J. Integrating gauge, radar and satellite rainfall. In: 2nd Workshop of the International Precipitation Working Group, CGMS-IPWG/WMO, Monterey, USA. Online Proceedings, http://www.isac.cnr.it/ ipwg/meetings/monterey-2004/pdf/Filho.pdf, 2004.

PEREIRA FILHO, A.J.; BARROS, M.T.L. Flood warning system for megacities: a Brazilian perspective. In: International Conference on Hydrology in a Changing Environment, Exeter: British Hydrological Society, v. 3, n. 14, p. 331-338, 1998.

PEREIRA FILHO, A.J.; CRAWFORD, K.C.; HARTZELL, C.L. Improving WSR-88D hourly rainfall estimates. Weather and Forecasting, v. 13, n. 4, p. 1016-1028, 1998.

PEREIRA FILHO, A.J.; MASSAMBANI, O.; HALLAK, R.; KARAM, H.A. Hydrometeorologycal forecast system for the Metropolitan Area od São Paulo. In: World Weather Research Program Symposium on Nowcasting and Very Short Range Forecasting, 2005, Toulouse. World Weather Research Program Symposium on Nowcasting and Very Short Range Forecasting. Toulouse, France, 2005.

PEREIRA FILHO, A.J.; NEGRI, A.J.; NAKAYAMA, P.T. An intercomparison of gauge, radar and satellite rainfall in the tropics. In: 1st Workshop on Precipitation Measurements, IPWG/CGMS/WMO, Madri, v. 1. p. 23-27.

PRUSKI, F.F.; PEREIRA, S.B.; NOVAES, L.F.; SILVA, D.D.; RAMOS, M.M. Precipitação média anual e vazão específica média de longa duração, na Bacia do São Francisco. Revista Brasileira de Engenharia Agrícola e Ambiental, v. 8, n. 2-3, p. 247-253, 2004.

TUCCI, C.E.M. Modelos Hidrológicos. Porto Alegre: Editora da Universidade Federal do Rio Grande do Sul, 1998.

VALVERDE, M.C.; MARENGO, J.A. Extreme rainfall indices in the hydrographic basins of Brazil. Open Journal of Modern Hydrology, v. 4, n. 1, p. 10-26, 2014.

VEMADO, F. Sea Breeze Circulation Analysis and its Impacts Over Metropolitan Area of São Paulo Precipitation Using ARPS Model. M.Sc. Dissertation, IAGUSP, 2012. 
XUE, M.; DROEGEMEIER, K.K.; WONG, W.; SHAPIRO, A.; BREWSTER, K. Advanced Regional Prediction System Users Guide. Oklahoma: University of Oklahoma, 380 pp, 1995.

XUE, M.; DROEGEMEIER, K.K.; WONG, W.; SHAPIRO, A.; BREWSTER, K.; CARR, F.; WEBER, D.; LIU, Y.; WANG, D.H. The Advanced Regional Prediction System (ARPS) - A multi-scale non-hydrostatic atmospheric simulation and prediction model. Part II: Model physics and applications. Meteorology and Atmospheric Physics, v. 76, n. 1, p. 143-165, 2001.

XUE, M.; DROEGEMEIER, K.K.; WONG, W. The Advanced Regional Prediction System (ARPS) - A multi-scale no hydrostatic atmospheric simulation and prediction model. Part I: Model dynamics and verification, Meteorology and Atmospheric Physics, v. 75, n. 3, p. 161-193, 2000.

XUE, M.; MARTIN, W.J. A high-resolution modeling study of the 24 May 2002 dryline case during IHOP. Part II: Hori- zontal convective rolls and convective initiation. Monthly Weather Review, v. 134, n. 1, p. 172-191, 2006.

XUE, M.; WANG, D.H.; GAO, J.; BREWSTER, K.; DROEGEMEIER, K.K. The Advanced Regional Prediction System (ARPS), storm-scale numerical weather prediction and data assimilation. Meteorology and Atmospheric Physics, v. 82, n. 1, p. 139-170, 2003.

ZHENG, W.; WEI, H.; WANG, Z.; ZENG, X.; MENG, J.; EK, M.; MITCHELL, K.; DERBER, J. Improvement of daytime land surface skin temperature over arid regions in the NCEP GFS model and its impact on satellite data assimilation. Journal Geophysics Research, v. 117, n. D06117, 2012.

License information: This is an open-access article distributed under the terms of the Creative Commons Attribution License (type CC-BY), which permits unrestricted use, distribution and reproduction in any medium, provided the original article is properly cited. 